\title{
Endophyte inoculation enhances Ulmus minor resistance to Dutch elm disease
}

Footnote to the title: Elm endophytes and Dutch elm disease resistance

Martínez-Arias, $\mathrm{C}^{1}$; Sobrino-Plata, J¹; Ormeño-Moncalvillo, S¹; Gil, L ${ }^{1}$; Rodríguez-Calcerrada, J ${ }^{1}$ and Martín, $\mathrm{JA}^{1^{*}}$.

${ }^{1}$ Departamento de Sistemas y Recursos Naturales, ETSI Montes, Forestal y del Medio Natural, Universidad Politécnica de Madrid, Madrid, 28040 Spain

*Author for correspondence: Juan Antonio Martín García. Tel: +34 910671758. Email: juan.martin.garcia@upm.es 


\section{Abstract:}

Certain fungal endophytes are known to improve plant resistance to biotic stresses in forest trees. In this study, three stem fungal endophytes belonging to classes Cystobasidiomycetes, Eurotiomycetes and Dothideomycetes were selected from 210 isolates for their potential as enhancers of Ulmus minor resistance to Ophiostoma novo-ulmi. We evaluated phenotypic traits of these endophytes that could be beneficial for inhibiting $O$. novo-ulmi in the host plant. Under in vitro conditions, the Dothideomycetous isolate YCB36 strongly inhibited O. novo-ulmi growth, released antipathogenic VOCs, chitinases and siderophores, and overlapped with the pathogen in nutrient utilization patterns. These functional traits could explain the $40 \%$ reduction in leaf wilting due to $O$. novo-ulmi in elm trees pre-inoculated with this endophyte. Ulmus minor trees inoculated with this endophyte showed increased leaf stomatal conductance and higher concentrations of flavonoids and total phenolic compounds in xylem tissues, suggesting induction of defence metabolism.

Keywords: antibiosis, biocontrol, Cystobasidium, Dutch elm disease, resistance, Dothideomycetes, elm, endotherapy, Exophiala, fungal endophytes. 


\section{Introduction}

In natural ecosystems, plants host a broad spectrum of microbes, especially fungi and bacteria that can colonize the plant surface as epiphytes or inner plant tissues as endophytes. When living inside plants, some endophytes act as mutualistic symbionts, assisting plant functioning, survival and fitness (Carroll, 1988; Schulz and Boyle, 2005; Rodríguez et al., 2009; Hardoim et al., 2015; Vandenkoornhuyse et al., 2015). Fungal endophytes have received considerable attention in recent years because of their impact on plant fitness and plant responses to biotic and abiotic stressors (Singh et al., 2011; Lata et al., 2018; Rabiey et al., 2019), and for being a potential source of bioactive compounds (Richardson et al., 2015; McMullin et al., 2018; Tanney et al., 2018). The role of fungal endophytes in plant resilience is especially important in trees, which face extreme weather conditions and recurring pathogen and insect attacks during their long lifespan (Lau et al., 2017; Terhonen et al., 2019, Martínez-Arias et al., 2020).

Endophytic fungi can shape host resistance to biotic stressors through several mechanisms (Witzell and Martín, 2018). Some of these are based on direct interaction between endophytes and pathogens, such as mycoparasitism, competitive exclusion by substrate consumption, and inhibition of the pathogen by extracellular enzymes released by the endophyte, e.g. by proteases or chitinases, which are able to degrade the hyphal cell wall of pathogens (Guthrie and Castle, 2006; dos Reis Almeida et al., 2007; Orlandelli et al., 2015). Indirectly, endophytes can stimulate the defence response of the plant by altering different signal transduction pathways, sometimes related with jasmonic or salicylic acid signalling(Shoresh et al., 2010; Fesel and Zuccaro, 2016; Martínez-Medina et al., 2017; Khare et al., 2018; Naidoo et al., 2019). Some endophytes enhance plant growth by synthesizing gibberellins (e.g. gibberellic acid, $\mathrm{GA}_{3}$ ) and auxins (e.g. indole-3-acetic acid, IAA) (Patten and Glick, 2002; Shi et al., 2009; Doty et al., 2011; Videira et al., 2012) or by improving nutrient acquisition (Della Monica et al., 2015; Surono and Narisawa, 2017; He et al., 2019), helping to counteract the negative effects of pathogen invasion. Phosphate solubilization (Nutaratat, 2014; Priyadharsini et al., 2017), siderophore emission 
(Moller et al., 2016; Haselwandter et al., 2020) and hydrogen cyanide (HCN) production (Haas and Defago, 2005) are the main mechanisms by which symbionts regulate availability of nutrients in soil. Siderophores and HCN have also been reported to aid biological control of plant pathogens by acting as antimicrobial compounds (Haselwandter et al., 2007; Rijavec and Lapanje, 2016). Endophyte-induced oxidative stress could enhance synthesis of plant antioxidant molecules and increase oxidative protection from biotic and abiotic stressors (White and Torres, 2010). Flavonoids and other phenolic antioxidants are some of the main molecules involved in these processes (Yang et al., 2016).

In recent decades, interest in the study of fungal endophytes and their use as biological control agents has increased (Arnold et al., 2003; Mejía et al., 2008; Fakhro et al., 2010; Martínez-Álvarez et al., 2016; Martínez-Arias et al., 2019; Quiring et al., 2019; Rabiey et al., 2019; Halecker et al., 2020). In forest trees, a successful example of biological control with fungal endophytes is the case of Phialocephala scopiformis, a rugulosin-producing endophyte with the ability to reduce the incidence of the Picea glauca budworm (Miller et al., 2008; Quiring et al., 2019). Effective applications of biocontrol agents require, preferably, locally adapted endophytes and easily cultured strains. Using local endophytes reduces the risk of incompatible interactions with the host plant and adverse environmental conditions for fungal development as well as higher and long-term fungal stability (Frasz et al., 2014); while easily cultured endophytes facilitate inoculum production. Multi-species microbial consortia can provide better results than single species due to the wider array of complex functions they perform (Brenner et al., 2008). However, studying a single species or a consortium of a few species is a necessary first step to evaluate specific functions and effects.

Dutch elm disease (DED), initially caused by Ophiostoma ulmi, was introduced into Europe and North America by global trade in the first half of the 20th century, being one of the earliest examples of alien diseases threatening native forests. The current DED pandemic is caused by Ophiostoma novo-ulmi (Sordariomycetes), which is transmitted into healthy elm trees through 
bark beetles of the genera Scolytus and Hylurgopinus. O. novo-ulmi spreads within xylem vessels, causing blockage and embolism (Brasier and Buck, 2001; Martín et al., 2019). Among the various biocontrol agents studied to reduce the impact of DED (Scheffer et al., 1990; Solla and Gil, 2003), fungal endophytes have received increasing attention in recent years (Martín et al., 2013; Blumenstein et al., 2015; Martín et al., 2015). In elms, distinct fungal assemblages were found in the xylem of susceptible and tolerant genotypes (Martín et al., 2013). Some of these endophytes were isolated and tested against $O$. novo-ulmi in vitro and in field plot assays (Martín et al., 2015), and some showed the ability to reduce DED symptoms. However, environmental factors and host genotype appeared to alter the behaviour and spread of the inoculated fungi, providing an unstable protective effect (Martín et al, 2015).

In this work, we aimed to evaluate three additional elm fungal endophytes for their use as biocontrol candidates against DED. For this purpose, we analyzed parameters that could be relevant for the successful inhibition of the pathogen by endophytes or for increasing host resistance, in both cases decreasing host damage. We selected three fungal endophytes from a collection of 210 isolates following two criteria. The first criterion was based on earlier metabarcoding research by our group that revealed a close association between the abundance of operational taxonomic units within classes Cystobasidiomycetes and Eurotiomycetes and the level of host resistance to DED (Macaya-Sanz et al., 2020). Considering this result, we hypothesize that elm endophytes belonging to these fungal classes exhibit functional traits involved in $U$. minor resistance to DED. The second criterion was based on other research showing that although most endophytes are able to reduce the growth of $O$. novo-ulmi in in vitro dual tests to some extent, mainly through substrate competition or weak antibiosis, only a few endophytes are able to strongly inhibit pathogen growth by antibiosis (Martín et al., 2015). Therefore, we further hypothesize that fungal endophytes exhibiting strong antibiotic activity towards 0 . novo-ulmi have the potential to reduce 0 . novo-ulmi spread in planta and consequently decrease disease symptoms. 
Two endophytes representative of classes Cystobasidiomycetes and Eurotiomycetes, and an additional Dothideomycetous isolate which showed strong in vitro antibiosis towards $O$. novoulmi were selected for this work. To evaluate the biocontrol potential of these endophytes we performed four specific studies to: i) characterize in vitro the type of interaction and the antibiotic activity of the three selected endophytes against $O$. novo-ulmi, ii) determine the nutrient metabolism, nutrient uptake ability and production of plant growth-promoting compounds in vitro by the endophytes, iii) evaluate the plant colonization ability of the endophytes and their protective effect against 0 . novo-ulmi in a field assay with 6-year-old susceptible $U$. minor trees, and iv) study the plant functional and chemical response to the endophytes to explain the protective effect against the pathogen.

\section{Material and methods}

\subsection{Fungal material}

Three fungal endophytes isolated from elm twigs and named YM11, P5 and YCB36 were selected for the experiments. The strains were deposited in the Spanish Type Culture Collection (CECT) with the codes CECT 13193, CECT 13192, and CECT 21178, respectively. The endophytes are from a collection of fungi that includes 210 isolates obtained from U. minor trees in the last 10 years, conserved by the Spanish elm breeding programme. The three selected fungi were isolated in 2014 and 2015 from three U. minor genotypes tolerant to DED (Martín et al., 2015) growing in a conservation plot at "Puerta de Hierro" Forest Breeding Centre, Madrid (Spain, $40^{\circ}$ $27^{\prime} 24^{\prime \prime} \mathrm{N} ; 3^{\circ} 45^{\prime} 0^{\prime \prime} \mathrm{W} ; 600 \mathrm{~m}$. a.s.I.). Twig samples for fungal isolation were first deeply cleaned with sterilized distilled water, and then sterilized following the method III described in Schulz et al. (1993). The yeasts belong to the Eurotiomycetes (YM11) and the Cystobasidiomycetes (P5), two fungal classes commonly occurring in $U$. minor trees with high resistance to $O$. novo-ulmi (Macaya-Sanz et al., 2020). YM11 colonies growing in standard culture medium comprise a mixture of budding cells and hyphae, while P5 forms bud cell aggregates. Additionally, the YCB36 isolate, a filamentous fungus from the Dothideomycetes, was selected because it strongly inhibited 0 . novo-ulmi growth in preliminary in vitro dual culture screening tests (visual 
assessment). This fungus produces a dark halo around the colony when grown on $3.5 \%$ yeast extract agar (YEA), indicating release of metabolites that could cause inhibition in 0 . novo-ulmi growth. YCB36 had an in vitro growth of $3.89 \mathrm{~mm}$ per day when growing in YEA.

After initial isolation on YEA, $4 \times 4 \mathrm{~mm}$ plugs of each endophyte isolate were conserved in sterilized distilled water $\left(\mathrm{dH}_{2} \mathrm{O}\right)$ at $4{ }^{\circ} \mathrm{C}$ in the dark. Two months before the experiment, isolates were sub-cultured on YEA medium in the dark at $22^{\circ} \mathrm{C}$. These colonies were subcultured every 15 days onto fresh YEA medium and used as stock source for subsequent assays. For molecular identification of endophytes, isolates were grown on YEA medium over an autoclaved cellophane layer. Five hundred milligrams of the mycelium were harvested and ground with a pellet pestle. DNA extraction was carried out as described by Martínez-Arias et al. (2019). After DNA extraction, the two Internal Transcribed Spacers (ITS) of ribosomal DNA and the large subunit of the rRNA (LSU) were amplified through Polymerase Chain Reaction (PCR) for each fungal strain. The universal primers ITS1F (5'-CTTGGTCATTTAGAGGAAGTAA- $\left.3^{\prime}\right)$ and ITS4 (5'TCCTCCGCTTATTGATATGC-3') were used to amplify the ITS region following a protocol based on White and Bruns (1990). In the case of the LSU region, the primers LROR (5'ACCCGCTGAACTTAAGC-3') and LR5 (5'-ATCCTGAGGGAAACTTC- $3^{\prime}$ ) were selected according to Vilgalys and Hester (1990). In addition to the previous markers, some protein-coding genes were used for YM11 and YCB36 identification. Thus, the translation elongation factor 1-alpha (TEF1 $\alpha$ ) was amplified through the primers EF1-1018F (5'- GAYTTCATCAAGAACATGAT-3') and EF1-1620R (5' GACGTTGAADCCRACRTTGTC-3') (Stielow et al., 2015). YCB36 taxonomical assignment was also characterized through amplification of beta-tubulin (tub2/BenA) with the primers Bt2a (5'GGTAACCAAATCGGTGCTGCTTTC-3') and Bt2b (5'- ACCCTCAGTGTAGTGACCCTTGGC-3') (Glass and Donaldson, 1995), and the amplification of the gene for partial actin with the primers act512F (5'- ATGTGCAAGGCCGGTTTCGC-3') and act-738R (5'- TACGAGTCCTTCTGGCCCAT-3') (Carbone and Kohn, 1999). The amplification products were Sanger-sequenced, and sequences were annotated taxonomically based on the most similar sequence with taxonomic identity 
using the Genbank Basic Local Alignment Search Tool (BLASTn) of the National Centre for Biotechnology Information database (NCBI, MD, USA).

The O. novo-ulmi ssp. americana isolate SOM-1 used in the experiments (Martín et al., 2019) was isolated in 2014 from a 168-year-old U. minor tree in El Pardo (Madrid, Spain) and had an in vitro growth rate of $4 \mathrm{~mm}$ per day on $2 \%$ malt extract agar (MEA) at $20^{\circ} \mathrm{C}$. The identity of the pathogen was determined by assessments of colony morphology and growth rates at $20^{\circ} \mathrm{C}$ and $33^{\circ} \mathrm{C}$, according to Brasier (1981). To confirm species and subspecies identity, a molecular analysis of the isolate was performed according to Gibb and Hausner (2005), as described in Martín et al. (2019). The isolate was conserved as mycelial plugs immersed in sterilized $\mathrm{dH}_{2} \mathrm{O}$ and subcultured on MEA two months before the experiment, kept in the dark at $22{ }^{\circ} \mathrm{C}$, and subcultured every 15 days.

\subsection{In vitro characterization of fungal endophytes}

\subsubsection{Dual culture with O. novo-ulmi}

Each endophyte was co-cultured with $O$. novo-ulmi in petri dishes ( $90 \mathrm{~mm}$ in diameter). Mycelial plugs $(5 \times 5 \mathrm{~mm})$ of both the endophyte and the pathogen were subcultured from the actively growing colony edge and transferred to new dishes with YEA. Ophiostoma novo-ulmi and endophyte plugs were spaced $4 \mathrm{~cm}$ apart in the petri dish. In control plates, $O$. novo-ulmi was grown as a monoculture on one side of the petri dish. Three replicate plates per endophyte (dual cultures) and pathogen (monocultures) were used. Colony growth was measured at 3, 7, 10 and 12 days of incubation by scanning the growth area of each fungus using ImageJ software (http://imagej.nih.gob/ij/). Relative growth inhibition of 0 . novo-ulmi by endophytes was calculated by comparing $O$. novo-ulmi colony growth in control plates and endophyteconfronted plates (Chamberlain and Crawford, 1999; Kusari et al., 2013). The following interactions between the endophyte and the pathogen were also assessed qualitatively according to Mejía et al. (2008): i) antibiosis (the endophyte is able to reduce pathogen growth by the release of antifungal compounds without mycelial contact between the two colonies, and 
a halo is usually observed), ii) mycoparasitism (the endophyte is able to parasitize pathogen hyphae, impairing their growth), and iii) substrate competition (the endophyte is able to grow more efficiently than the pathogen, without evidence of an inhibition zone).

\subsubsection{Volatile antifungal assay}

To test the emission of antifungal volatile organic compounds (VOCs) produced by the three fungal endophytes, a VOC assay was performed as described by Chen et al. (2018). Fungal endophytes were cultured independently on petri dishes with YEA medium. Then, the lid was removed and the plate with the endophyte culture was confronted with another plate with an O. novo-ulmi culture on MEA medium. In the case of P5 and YM11, a $50 \mu \mathrm{l}$ drop containing 10 $\mathrm{mg} \mathrm{ml}^{-1}$ of yeast cells or mycelial fragments was deposited in the middle of the petri dish. YCB36 was subcultured directly using a mycelial plug from the colony edge, which was deposited in the middle of the plate. The two plates (endophyte vs $O$. novo-ulmi and control with no endophyte vs $O$. novo-ulmi) were sealed together with parafilm and incubated vertically at $22{ }^{\circ} \mathrm{C}$. Three replicates were performed for each endophyte. 0 . novo-ulmi mycelial growth was evaluated at 3, 7 and 10 days by scanning the plates and measuring the colony area using Image free software. Inhibition of $O$. novo-ulmi growth was quantified as described in the previous section.

\subsubsection{Antibiotic effect of liquid filtrates against $O$. novo-ulmi}

Endophyte antibiotic potential against $O$. novo-ulmi was evaluated by obtaining liquid filtrates from endophytes. The inoculum source for each liquid culture was obtained by growing each endophyte on YEA medium over an autoclaved cellophane layer. Once grown, endophyte fresh mycelia or yeast cells were harvested, adjusted to $5 \mathrm{mg} \mathrm{ml}^{-1}$ with sterile deionized water, and homogenized using an all-glass tissue homogenizer. For each endophyte, $100 \mu l$ of the fungal biomass homogenate was added to $70 \mathrm{ml}$ of yeast, malt and glucose liquid medium $\left(4 \mathrm{~g}^{-1}\right.$ yeast extract, $10 \mathrm{~g} \mathrm{l}^{-1}$ malt extract and $4 \mathrm{~g} \mathrm{l}^{-1}$ glucose; YMG) in Erlenmeyer flasks and grown in the dark at $22^{\circ} \mathrm{C}$ in an orbital shaker $(120 \mathrm{rpm})$. Three replicates were performed for each fungal strain. Glucose content in the liquid media was quantified periodically by the anthrone-sulphuric acid 
quantification method (Laurentin and Edwards, 2003) using 96-well microplates. The values were quantified according to a standard curve with known concentrations of glucose $(0-1000$ ppm). Once glucose was totally consumed (at around 25 days of growth), the culture was left to grow for two more weeks to allow secretion of fungal metabolites. After this period, the broth culture was filtered, first with Whatman ${ }^{\circledR}$ filter paper grade 1 (Whatman International Ltd, Maidstone, UK) and subsequently with a sterile $0.2 \mu \mathrm{m}$ PES syringe filter (Thermo Fisher Scientific, Waltham, MA, USA), to separate broth and fungal biomass. The filtrates were preserved at $4{ }^{\circ} \mathrm{C}$ until use. The antibiotic effect of the liquid filtrates was assessed by growing O. novo-ulmi spores in their presence in microplates. To obtain O. novo-ulmi spores, mycelial fungal plugs were grown in Erlenmeyer flasks with Tchernoff's liquid medium (Tchernoff, 1965) at $22^{\circ} \mathrm{C}$ in the dark, under constant shaking to induce sporulation. Three days later spores were collected by centrifugation and adjusted to $10^{6}$ cells $\mathrm{ml}^{-1}$ using a haemocytometer. Six wellreplicates were used for each treatment and control group. Microplates were incubated at $22^{\circ}$ $C$ in the dark and growth was evaluated at $0,2,7,9$ and 11 days by reading the optical density (OD) at 630 nm, using a spectrophotometer (ELx808, BioTek, Winooski, VE, USA) (Martín et al., 2010). To evaluate the effect of fungal filtrates, $100 \mu$ l of filtrate was mixed with $100 \mu \mathrm{l}$ of $O$. novo-ulmi spores resuspended in 0 . novo-ulmi liquid filtrate, obtained following the same protocol as for the endophyte liquid filtrates $\left(100 \mu \mathrm{l}\right.$ of $5 \mathrm{mg} \mathrm{ml}^{-1}$ homogenized fresh mycelia grown in YMG for 40 days). Pathogen growth in endophyte liquid filtrates (testing wells) was compared with growth in control wells containing $100 \mu$ l of O. novo-ulmi spores resuspended in their own liquid filtrate, mixed with a further $100 \mu \mathrm{l}$ of 0 . novo-ulmi liquid filtrate. Additional background control wells containing endophyte or 0 . novo-ulmi filtrates only (without living cells) were used to subtract the OD of the filtrates from the testing wells, thus measuring only the increased OD due to $O$. novo-ulmi growth. Background control wells also determined that culture filtrates contained no contamination. Comparison between treatment and control groups permitted calculation of $O$. novo-ulmi growth inhibition due to filtrates. 


\subsubsection{Proteolytic and chitinolytic activities}

Extracellular protease and chitinase production by each fungus was evaluated in petri dishes with specific culture media (described below) at 5, 8, 12, 15, 20 and 23 days of incubation. Plugs of the fungal colonies were grown at $22{ }^{\circ} \mathrm{C}$ in the dark. Protease activity was determined on skim milk agar plates (SMA: $28 \mathrm{~g} \mathrm{l}^{-1}$ skim milk powder, $5 \mathrm{~g} \mathrm{l}^{-1}$ tryptone, $2.5 \mathrm{~g} \mathrm{l}^{-1}$ yeast extract, $1 \mathrm{~g}$ $\mathrm{I}^{-1}$ glucose, $15 \mathrm{~g} \mathrm{l}^{-1}$ agar; $\mathrm{pH}$ 7.0). Positive activity was measured by production of a clear halo surrounding the colonies (Mayerhofer et al., 1973). The halo area $\left(\mathrm{cm}^{2}\right)$ was calculated by subtracting the colony area from the area inside the halo contour surrounding the colony. Chitinase detection medium was prepared as described by Agrawal and Kotasthane (2012). Colloidal chitin was obtained according to Castro et al. (2011). Bromocresol purple dye (SigmaAldrich, Darmstadt, Germany) permitted visualization of chitin degradation. A colour shift from yellow to purple around the colony indicates positive chitinase activity. The area showing a colour change was quantified $\left(\mathrm{cm}^{2}\right)$ by subtracting the colony area from the area of the colourchanged halo. Six replicates were performed for each fungus and activity.

\subsubsection{Nutrient acquisition mechanisms}

Siderophore and HCN production and phosphate solubilization potential were evaluated for each fungus at $5,8,12,15,20$ and 23 days of incubation. Siderophore emission was examined using the Chrome Azurol S (CAS) agar medium. CAS was prepared following the protocol of Schwyn and Neilands (1987), in which 60.5 mg CAS (Merck KGaA, Darmstadt, Germany) was dissolved in $\mathrm{dH}_{2} \mathrm{O}$ and mixed with $10 \mathrm{ml}$ of iron (III) solution ( $\left.1 \mathrm{mM} \mathrm{FeCl}_{3} \cdot 6 \mathrm{H}_{2} 0,10 \mathrm{mM} \mathrm{HCl}\right)$. After this, hexadecyltrimethylammonium bromide (HDTMA; Sigma-Aldrich, Darmstadt, Germany) was dissolved in water, mixed with CAS solution and autoclaved at $121^{\circ} \mathrm{C}$. The basal medium was prepared using $0.5 \%$ succinic acid, $0.4 \% \mathrm{KH}_{2} \mathrm{PO}_{4},\left(\mathrm{NH}_{4}\right)_{2} \mathrm{SO}_{4}$ and $2 \%$ agar at pH 5.3. The HDTMACAS solution was slowly mixed until the desired blue colour was obtained. Plugs of fungal colonies were grown in six replicate petri dishes containing HDTMA-CAS agar medium at $22{ }^{\circ} \mathrm{C}$ 
in the dark. Positive siderophore activity was evaluated by colour change from blue to yellow, subtracting the colony area from the area of the colour-changed halo $\left(\mathrm{cm}^{2}\right)$.

The hydrogen cyanide (HCN) production test was performed based on Millar and Higgins (1970). HCN solution was prepared by mixing $0.5 \%$ picric acid and $2 \%$ sodium carbonate. Sterilized Whatman ${ }^{\circledR}$ filter papers were soaked in HCN solution and placed on the lid of YEA petri dishes where fungal plugs were cultured. Then, petri dishes were sealed with parafilm and incubated in the dark at $22{ }^{\circ} \mathrm{C}$. Six replicates were performed for each fungus. Colour change in the filter paper indicates positive $\mathrm{HCN}$ release by the fungi, due to the ability of $\mathrm{HCN}$ to reduce picric acid to isopurpuric acid. Activity was scored as negative (no colour change) or positive (brown to reddish brown).

Phosphate solubilization was performed in Pikovskaya agar medium with the addition of $0.3 \%$ insoluble calcium triphosphate (Sigma-Algrich, Darmstadt, Germany). Endophyte plugs were grown in six replicate petri dishes with Pikovskaya agar medium at $22{ }^{\circ} \mathrm{C}$ in the dark. The presence of a halo or clear area around the colony, indicating phosphate solubilization potential, was measured as halo area $\left(\mathrm{cm}^{2}\right)$.

\subsubsection{Nutrient utilization patterns and chemical sensitivity}

Nutrient utilization patterns and the sensitivity of the endophytes and the pathogen to a series of inhibitory substrates were evaluated using in-house configured phenotypic microarrays, following the methodology described by Blumenstein et al. (2015). Fungal inocula were prepared as described in the section "Antibiotic effect of liquid filtrates against 0 . novo-ulmi", but in this case the fungal biomass was resuspended in Murashige and Skoog (MS) liquid medium. Fungal growth on different nutrients was evaluated in 96-well microplates by measuring OD at $630 \mathrm{~nm}$ using an ELx808 spectrophotometer after 9 days of incubation. The following carbon sources were added individually to the MS medium: glucose, fructose, sucrose, cellobiose, pectin, xylose, maltose, starch and carboxymethyl-cellulose. All nutrient solutions 
were adjusted to a final concentration of $0.25 \mathrm{M}$ carbon atoms. Various metabolites with potential to inhibit fungal development were added individually to the MS medium: gallic acid $\left(1 \mathrm{gl}^{-1}\right)$, salicylic acid $\left(0.05 \mathrm{~g} \mathrm{l}^{-1}\right)$, tannic acid $\left(1 \mathrm{~g} \mathrm{l}^{-1}\right)$, veratryl alcohol $\left(2.37 \mathrm{~g} \mathrm{l}^{-1}\right)$, quercetin $(0.01 \mathrm{~g}$ $\left.\mathrm{I}^{-1}\right)$, catechin $\left(1 \mathrm{~g}^{-1}\right)$, thymol $\left(0.05 \mathrm{~g}^{-1}\right)$ and ethanol (5\%). Carbon consumption by endophytes was compared with carbon consumption by $O$. novo-ulmi using the Niche Overlap Index (NOI). NOI was calculated as the number of carbon sources consumed by the endophyte and the pathogen, divided by the number of sources consumed by the pathogen (Lee and Magan, 1999). A NOI value of 0.9 or above indicates a high degree of niche overlap and a competitive disadvantage for the pathogen (Blumenstein et al., 2015).

\subsubsection{Phytohormone production by endophytes and the pathogen}

Ability of the three endophytes and $O$. novo-ulmi to produce auxins and gibberellins was evaluated. For indole-3-acetic acid (IAA) detection, the four fungi were grown separately in $2 \%$ malt extract broth (MEB) containing $0.2 \%$ (v/v) L-tryptophan. Erlenmeyer flasks contained $30 \mathrm{ml}$ medium and $60 \mu \mathrm{l}$ homogenized fungal biomass adjusted to $5 \mathrm{mg} \mathrm{ml}^{-1}$. Flasks were kept in the dark at $22{ }^{\circ} \mathrm{C}$ under constant shaking for 15 days. IAA production was estimated following the colorimetric protocol, using Salkowski reagent described in Gang et al. (2019) prepared by mixing $0.5 \mathrm{M}$ ferric chloride $\left(\mathrm{FeCl}_{3}\right)$ and $35 \%$ perchloric acid $\left(\mathrm{HClO}_{4}\right)$. Three replicates were performed for each fungus. To quantify the IAA produced by each fungus, three aliquots of each broth were selected and centrifuged at 10,000 rpm for $10 \mathrm{~min}$. After that, $500 \mu \mathrm{l}$ supernatant was mixed with $1 \mathrm{ml}$ Salkowski reagent and incubated for $25 \mathrm{~min}$ in the dark. Absorbance was read at $530 \mathrm{~nm}$, and the concentration of IAA produced by each isolate was determined using a standard curve of pure IAA (Sigma-Aldrich, Darmstadt, Germany) ranging from 0 to $1000 \mu \mathrm{g} \mathrm{ml}$ 1.

Gibberellic acid $\left(G_{3}\right)$ released by each fungus was quantified using the liquid filtrates obtained for the antibiotic evaluation (see section 2.2.3). $\mathrm{GA}_{3}$ quantification was performed by selecting three aliquots of the filtrate and adjusting the $\mathrm{pH}$ to 1.5 using $0.1 \mathrm{M} \mathrm{HCl}$. Then, $2 \mathrm{ml}$ of the 
acidified liquid medium was mixed with $4 \mathrm{ml}$ ethyl acetate, vortexed vigorously and centrifuged at 5,000 rpm for $10 \mathrm{~min}$ (Holbrook et al., 1961). This process was repeated two more times, after which the organic phase was mixed, evaporated and suspended in absolute ethanol. Absorbance was read at $254 \mathrm{~nm}$ and recorded at $20 \mathrm{~s}$ intervals for 2 min according to Berríos et al. (2004). $\mathrm{GA}_{3}$ concentration was estimated using $\mathrm{GA}_{3}$ (Sigma-Aldrich, Darmstadt, Germany) standard solutions in ethanol ranging from $0.1 \mathrm{~g}^{-1}$ to $1 \mathrm{~g}^{-1}$.

\subsection{In vivo experiment}

\subsubsection{Plant material}

The plant material used in the in vivo experiment was produced in 2012 as part of the regular activities of the Spanish elm breeding programme at "Puerta de Hierro" Forest Breeding Centre. Controlled crosses were performed between two U. minor genotypes (M-CC1 and AL-AN1). To properly evaluate offspring susceptibility to $\mathrm{DED}$, the seedlings obtained $(\mathrm{N}=37)$ were cloned through aerial cuttings. After the susceptibility tests, four seedlings showing moderate to high DED susceptibility (50-70 \% leaf wilting 60 days after 0 . novo-ulmi inoculation) were selected and 30 to 34 clonal replicates of each seedling were planted in an experimental plot in 2014 (Table 1). The plot had a complete random design and plants were spaced $1 \times 1.4 \mathrm{~m}$ apart. Plants were regularly watered in spring and summer to avoid water stress. One highly DED resistant commercial clone (Sapporo, $\mathrm{N}=8$ ) and one highly DED susceptible clone ( $\mathrm{M}-\mathrm{PZ3}, \mathrm{N}=8)$ were also included in the plot to confirm the virulence of the O. novo-ulmi isolate.

\subsubsection{Experimental design}

In planta inoculations were performed in May 2017, when plants were 6-years old. Two endophyte cell suspensions were prepared (as described in the next section): (i) a mixture of P5 and YM11; and ii) YCB36. These suspensions were inoculated into the vascular system in the middle of the trunk using an endotherapy device (BITE, Padova, Italy). Ophiostoma novo-ulmi inoculations were performed with a bud-cell suspension (prepared as described in the next section) $5 \mathrm{~cm}$ below the endophyte inoculation point, on the opposite side of the trunk. 
Pathogen spores were delivered into the xylem sap stream through a transverse cut made with a sharp blade (Solla et al., 2005). Four treatments were applied (Fig. S1): (i) Control plants with no endophyte or pathogen inoculation (E-O-); (ii) Plants inoculated with endophytes (P5+YM11 or YCB36) without subsequent $O$. novo-ulmi inoculation (E+O-); iii) Plants inoculated with $O$. novo-ulmi without previous endophyte inoculation (E-O+); and iv) Plants inoculated with endophytes subsequently inoculated with the pathogen ( $\mathrm{E}+\mathrm{O}+$ ) (Table 1). In treatments i) to iii), plants not inoculated with either the endophytes or the pathogen (E- and O- treatments) received sterile distilled water. Endophyte and 0 . novo-ulmi inoculations, and their corresponding control treatments, were performed on 1st May and 16th May, respectively (Fig. S1).

\subsubsection{Inoculum preparation}

To obtain the endophyte inoculum, a liquid suspension of bud cells (for YM11 and P5) or hyphal fragments (for YCB36) were prepared. Endophytes were grown in petri dishes containing YEA medium, with (YM11 and YCB36) or without (P5) an autoclaved cellophane layer, for 10 days at $22^{\circ} \mathrm{C}$ in the dark. $\mathrm{P} 5$ yeast cells were scraped from the agar using a sterile spatula and suspended in sterile distilled water. YM11 formed a colony of dense, hard agglomerates of bud cells, requiring the use of an all-glass tissue homogenizer to obtain a homogeneous cell suspension. YCB36 did not produce a sufficient quantity of conidia and therefore spores were replaced by mycelial fragments also obtained using an all-glass tissue homogenizer, first with a large clearance pestle and then with a small one ( $\sim 50$ strokes with each). We then poured the resulting suspension over sterilized cotton wool, so the longer fungal hyphae were collected into the cotton wool. The resulting suspension was quite homogenous, with hyphal fragments of 14 cells/fragment. Aqueous suspensions of yeast cells or mycelial fragments were adjusted using a haematocytometer to obtain a final inoculum concentration of $2 \times 10^{6}$ cells $\mathrm{ml}^{-1}$ for the mixture of P5 and YM11 ( $10^{6}$ cells ml ${ }^{-1}$ of each fungus) and approximately $10^{6}$ cells $\mathrm{ml}^{-1}$ for YCB36. 
To obtain O. novo-ulmi spores, mycelial fungal plugs were grown in Erlenmeyer flasks with Tchernoff's liquid medium (Tchernoff, 1965) at $22^{\circ} \mathrm{C}$ in the dark under constant shaking to induce sporulation. Three days later, spores were collected by centrifugation and adjusted to $10^{6}$ blastospores $\mathrm{ml}^{-1}$ using a haemocytometer.

\subsubsection{Leaf wilting evaluation}

Leaf yellowing and wilting are typical DED symptoms. As the disease progresses, a mixture of healthy and suffering foliage may be seen (Brasier and Buck, 2001) and the percentage of foliar wilting in the crown is a good indicator of tree decline (Solla et al., 2005). Leaf wilting for symptoms of 0 . novo-ulmi was evaluated in each tree at 30,60 and 120 days post inoculation (dpi) and also 1 year post-inoculation (ypi). Assessments were performed by three independent evaluators and the mean of the three scores was calculated for each tree and treatment. A representative leaf of the average wilting status of the tree was selected to measure leaf stomatal conductance. This measurement was made at the time of $O$. novo-ulmi inoculation and at $30 \mathrm{dpi}$ using an SC-1 leaf porometer (Decagon Devices, Washington, USA) in five trees per treatment, at midday on both occasions.

\subsubsection{In planta endophyte detection}

To evaluate plant colonization by endophytes, wood samples from control (E-O-) and endophyte-inoculated trees ( $\mathrm{E}+\mathrm{O}-$ ) were extracted using an increment borer at $75 \mathrm{dpi}$ and $1 \mathrm{ypi}$. Two samples per tree were taken, at 5 and $50 \mathrm{~cm}$ above the endophyte inoculation point. Three replicate trees per treatment were evaluated. Fungal DNA presence was quantified through quantitative PCR (qPCR). First, core wood samples were ground to a fine powder in a ball mill (Mixer mill MM 400, Retsch GmbH, Haan, Germany) and DNA was extracted using the Norgen plant/fungi DNA isolation kit (Norgen Biotek Corp., Thorold, ON, Canada), obtaining high yield and quality scores. Primer sequences were designed within the sequences obtained by ITS Sanger sequencing of each fungus (described previously) using Primer3 Version 0.4.0 (http://bioinfo.ut.ee/primer3-0.4.0/primer3/) and following specific parameters for qPCR 
primer design (Udvardi et al., 2008). Specificity tests for the primers designed were performed by selecting 10 additional fungi available in our collection and amplifying fungal DNA through conventional PCR. If an amplification product was observed, the primer pair was discarded and new primer pairs were designed. Selected primer pairs were set as follows: the primer pair for P5 (forward primer: 5'-CAACGGATCTCTTGGCTCTC-3') reverse primer: 5'AACAGACATACTCTTCGGAATACC-3') created a 136 base-pair (bp) product, the primer pair for YM11 (forward primer: 5'- AGGAACTGGCCTCAAAGACA-3'/ reverse primer: 5'TCCTACCTGATCCGAGGTCA $-3^{\prime}$ ) created a $142 \mathrm{bp}$ product, and the primer pair for YCB36 (forward primer: 5'-AGTATACGCCGCCTTGACAC-3'/ reverse primer: 5'GTCGTAAAACATGGGGAACG-3') created a 130 bp product. Relative fungal DNA estimations were performed independently for each fungus using SSoFast EvaGreen ${ }^{\circledR}$ Supermix (Bio-Rad Laboratories, Irivine, CA, USA) in a CFX96 real-time PCR detection system thermocycler (Bio-Rad Laboratories, Irvine, CA, USA). Fungal DNA was standardized per quantity of plant DNA by amplifying a fragment of the $U$. minor ITS region (ITSUlmi) (forward primer: 5'ATATGTCAAAACGACTCTCGGCAAC-3'/ reverse primer: 5'-AACTTGCGTTCAAAGACTCGATGGT-3'). In triplicate, reactions contained $2 \mu \mathrm{l}$ sample DNA and $8 \mu \mathrm{l}$ master mix. Following a first denaturation step at $95^{\circ} \mathrm{C}$ for $30 \mathrm{~s}, 40$ cycles were performed at $95^{\circ} \mathrm{C}$ for $5 \mathrm{~s}$ and $60{ }^{\circ} \mathrm{C}$ for $30 \mathrm{~s}$. Each plate included two replicates of each sample: one for amplification of the specific fungal ITS, and the other for amplification of U. minor ITS. Three no-template controls were included for each primer pair. The amplification results were analysed and expressed as fungal presence relative to non-inoculated plants.

\subsubsection{Plant biochemical measurements}

Wood samples were extracted from trees showing a significant effect of the endophyte inoculation treatment on plant symptomatology, to measure non-structural carbohydrates, total phenolic and flavonoid content, and proline. The concentration of non-structural carbohydrates (NSC) was measured using a modified protocol from Maness (2010). Soluble 
sugars (SS) were extracted by incubating $50 \mathrm{mg}$ fresh material in $1 \mathrm{ml}$ of $80 \%$ ethanol. An aliquot of the ethanol extract was reserved for proline quantification (see below). The insoluble material in the pellet was used for starch determination. Sugar monomers from the ethanol extract or starch digestion were quantified by the anthrone-sulphuric acid colorimetric microassay, based on Laurentin and Edwards (2003), using 96-well microplates. The values were quantified according to standard curves with known concentrations of glucose, fructose and galactose (0$1000 \mathrm{ppm})$ in the case of SS, and only glucose $(0-1000 \mathrm{ppm})$ in the case of starch. Total NSC concentration was calculated by adding the concentrations of SS and starch.

Total phenolic content extraction was performed according to a microplate-adapted protocol described by Ainsworth and Gillespie (2007) and quantified using the Folin-Ciocalteu reagent (FC). Briefly, $20 \mathrm{mg}$ powdered wood was extracted in $1 \mathrm{ml}$ of $95 \%$ methanol under constant shaking in a mixer mill (Precellys, Bertin Instruments, Montigny-le-Bretonneux, France), then incubated at room temperature for $48 \mathrm{~h}$ in the dark. The supernatant was recovered and $200 \mu \mathrm{l}$ of the $\mathrm{F}-\mathrm{C}$ reagent at $10 \%(\mathrm{v} / \mathrm{v})$ was added per each $100 \mu \mathrm{l}$ of extract or standard. Finally, $800 \mu \mathrm{l}$ of $\mathrm{Na}_{2} \mathrm{CO}_{3} 700 \mathrm{mM}$ was added and incubated at room temperature for $2 \mathrm{~h}$. Absorbance was read at $765 \mathrm{~nm}$ and the values were quantified according to a standard curve with known concentrations of gallic acid ( $25 \mu \mathrm{M}-1.5 \mathrm{mM})$. Results were expressed as mg equivalent gallic acid per gram of fresh weight of sample.

Total flavonoid content was determined using the same extract obtained for total phenolic content and quantified by the colorimetric method described in Barreira et al. (2008), with slight modifications. Briefly, $177.5 \mu \mathrm{L}$ aliquots of each sample and $25 \mu \mathrm{L}$ aliquots of each standard point (diluted with $152.5 \mu \mathrm{L}$ deionized water) were mixed with $\mathrm{NaNO}_{2}$ (5\%, $7.5 \mu \mathrm{L}$ ). After 6 min, $15 \mu \mathrm{L}$ of a $10 \% \mathrm{AlCl}_{3} \cdot 6 \mathrm{H}_{2} \mathrm{O}$ solution was added, and after 5 min incubation at room temperature, $50 \mu \mathrm{L}$ of $1 \mathrm{M} \mathrm{NaOH}$ was added. The absorbance of each blank, consisting of the same sample mixtures but with deionized water instead of $10 \% \mathrm{AlCl}_{3} \cdot 6 \mathrm{H}_{2} \mathrm{O}$ solution, was subtracted from the test absorbance. The absorbance was read at $510 \mathrm{~nm}$ using a microplate reader and the values were 
quantified according to a standard curve with known concentrations of quercetin (0.2-1.0 mg $\mathrm{ml}^{-1}$ in ethanol). Results were expressed as mg equivalent quercetin per gram of fresh weight of sample.

Free proline content was determined with the same extract used for SS determination. Quantification was carried out using a microplate reader protocol (Carillo and Gibon, 2011). In each well, $50 \mu \mathrm{l}$ of the ethanolic extract, blank or proline standards (1-0.4-0.2-0.1-0.04 mM) was mixed with $100 \mu$ l of the reaction mix: $1 \%$ ninhydrin (w/v) in $60 \%$ acetic acid $(v / v)$ and $20 \%$ ethanol $(\mathrm{v} / \mathrm{v})$. Plates were incubated in a water bath at $95^{\circ} \mathrm{C}$ for $20 \mathrm{~min}$ and absorbance was read at $520 \mathrm{~nm}$. The readings were transformed to proline contents ( $\mathrm{nmol} \mathrm{mg^{-1 }} \mathrm{FW}$ ) according to Carillo and Gibon (2011).

\subsection{Statistical analysis}

The effect of endophytes on 0 . novo-ulmi growth in in vitro assays was tested with one-way ANOVA and the post-hoc Fisher's Least Significant Difference (LSD) test $(P<0.05)$. The area of the halo formed by the four fungal strains was compared using a one-way ANOVA test followed by Fisher's LSD test $(P<0.05)$ to identify differences in protease, chitinase and siderophore emission between isolates. The effect of inhibitory substances and carbon sources on fungal growth was represented with a two-way joining cluster analysis using the heatmap function in the "pheatmap" package in R-studio (R Core Team 2017). Euclidean distances were used in the clustering of fungal endophytes or chemicals. Differences in wilting symptoms, leaf stomatal conductance and biochemical variables among treatments were analysed with one-way ANOVA test followed by Fisher's LSD test $(P<0.05)$. To observe differences in wilting symptoms among elm clones due to O. novo-ulmi, a factorial ANOVA was performed, taking the clone and O. novoulmi treatments as factors. Fungal quantification through quantitative PCR was performed for each sample at 5 and $50 \mathrm{~cm}$ from the inoculation point with three technical replicates per PCR plate. The cycle threshold value $(\mathrm{Ct})$ obtained for the plant and endophyte ITS in each sample was transformed to double delta $\mathrm{Ct}(\Delta \Delta \mathrm{Ct})$. Then, $\Delta \Delta \mathrm{Ct}$ of the endophyte was normalized to $\Delta \Delta \mathrm{Ct}$ 
of plant ITS. The normalized values of endophyte- inoculated plants were relativized to control plants, obtaining the fold-change of endophyte presence. These values were analysed with a one-way ANOVA test to determine whether there were significant differences between inoculated and non-inoculated trees.

Analyses were run using STATISTICA version 8.0 (StatSoft, Tulsa, OK, USA) and R software (R Core Team 2017). In all cases, normality was confirmed before ANOVA analysis with skewness and kurtosis values and the Kolmogorov-Smirnov test.

\section{Results}

\subsection{Molecular identification of fungal endophytes}

According to the top BLAST hits for ITS and LSU sequencing the P5 endophyte is assigned to the genus Cystobasidium (Cystobasidiomycetes) and YM11 to Exophiala (Eurotiomycetes) (Table 2). However, the top BLAST hit for TEF1 $\alpha$ sequence of YM11 assigned it to Knufia, although with lower percentage of identity than ITS and LSU sequences (Table 2). Results for YCB36 indicate that this fungus belongs to the Phaeosphaeriaceae family (Dothideomycetes). According to the LSU sequence the top hit corresponded to the genus Hydeomyces (99.41\% identity), while the rest of the markers did not provide significant coverages and/or identities at the genus level (Table 2). Therefore, it might be an undescribed fungus within Phaeosphaeriaceae.

\subsection{In vitro fungal endophyte characterization}

\subsubsection{In vitro endophyte-pathogen interactions}

O. novo-ulmi growth was reduced when confronted with YCB36 and P5 endophytes, but not with YM11 despite this endophyte displaying some visible slight inhibition of O. novo-ulmi (Table 3; Fig. S2A, D). When confronted with YCB36, 0 . novo-ulmi growth was reduced between $28.05 \pm$ $3.59 \%$ and $37.62 \pm 5.32 \%$ throughout the experiment (Table 3; Fig. S2A, D). Volatiles emitted by YCB36 and P5 also inhibited 0 . novo-ulmi growth (Table 3). The highest inhibition was observed with YCB36 (32.82 $\pm 5.54 \%)$ and a moderate inhibition was observed with P5 (11.02 \pm $3.28 \%$ ) (Table 3; Fig. S2B, D). 


\subsubsection{Antibiotic traits}

O. novo-ulmi growth was reduced when cultured in liquid media containing YM11 and YCB36 liquid filtrates (Table 3; Fig. S2C). YCB36 filtrate was able to reduce 0 . novo-ulmi growth by 55.94 $\pm 0.96 \%$ ( $P<0.01$; Table 3; Fig. S2C), while YM11 filtrate reduced $O$. novo-ulmi growth by 28.74 $\pm 2.9 \%$ (Fig. S2C). P5 filtrate did not reduce O. novo-ulmi growth (Table 3; Fig. S2C). Proteolytic activity varied considerably among isolates, with 0 . novo-ulmi showing a halo formation of 28.73 $\mathrm{cm}^{2}$ (Table 4, Fig. S3). Endophyte P5 had low proteolytic activity, and the halo area was barely visible $\left(1.33 \pm 0.06 \mathrm{~cm}^{2}\right)$. In contrast, YCB36 and YM11 showed a clear halo around the colony, which was significantly greater for YCB36 than for YM11 $\left(10.28 \pm 2.48\right.$ and $5.75 \pm 0.71 \mathrm{~cm}^{2}$, respectively) (Table 4; Fig. S3). In the case of chitinolytic activity, YCB36 produced a clear bluepurple halo surrounding the colony (18.19 $\mathrm{cm}^{2}$ at day 5 and $49.85 \pm 1.63 \mathrm{~cm}^{2}$ at day 20$)$, while the other endophytic fungi had no chitin degradation ability (Table 4, Fig. S3). Chitinase activity in O. novo-ulmi became visible at day $20\left(6.46 \pm 1.96 \mathrm{~cm}^{2}\right)$ (Table 4, Fig. S3).

\subsubsection{Nutrient acquisition mechanisms and nutritional niche}

Only the $O$. novo-ulmi and YCB36 isolates secreted siderophores into the medium (Table 4, Fig. S3). YCB36 exhibited greater halo formation than O. novo-ulmi at day 20 (7.90 \pm 0.44 vs $5.39 \pm$ $\left.0.98 \mathrm{~cm}^{2}\right)(P<0.05)$ (Table 4, Fig. S3). However, neither HCN nor phosphate were solubilized by any of the fungal strains evaluated (Table 4).

The carbon utilization pattern and chemical sensitivity to inhibitory substances of each isolate are shown in the two-way joining cluster graph (Fig. 1). As expected, the analysis of the substrates (vertical axis) provided two clusters: the carbon sources on one side and the inhibitory metabolites on the other. The clustering of the fungal isolates (horizontal axis) separated P5 from the other fungi, coinciding with the taxonomic division of the fungi into Basidiomycota and Ascomycota, respectively. The clustering also separated the two ascomycetous endophytes (YM11 and YCB36) from the pathogen. P5 and O. novo-ulmi were less affected by inhibitory metabolites (e.g., by gallic acid and thymol), while YM11 and 0 . novo-ulmi 
showed the highest growth in the presence of certain carbon sources (e.g., sucrose, glucose and fructose).

Only considering carbon sources, the NOI of $O$. novo-ulmi with regard to P5, YM11 and YCB36 was $0.78,0.78$ and 1 , respectively, indicating a putative high niche overlap between the pathogen and YCB36.

\subsubsection{Growth promotion potential}

The three endophytes and the pathogen produced IAA. O. novo-ulmi produced $191.23 \mu \mathrm{g}$ IAA g-

${ }^{1}$ fungal dry weight. P5 produced $1110.14 \mu \mathrm{g} \mathrm{IAA} \mathrm{g}^{-1}$ fungal dry weight and was the endophyte with the highest IAA production (Fig. 2A). GA 3 production was similar in O. novo-ulmi, YCB36 and P5 $\left(0.196 \pm 0.014 \mathrm{~g} \mathrm{l}^{-1}, 0.258 \pm 0.010 \mathrm{~g} \mathrm{l}^{-1}\right.$ and $0.173 \pm 0.020 \mathrm{~g} \mathrm{l}^{-1}$, respectively), while YM11 produced the lowest $\mathrm{GA}_{3}$ concentration $\left(0.108 \pm 0.042 \mathrm{~g} \mathrm{l}^{-1}\right)$ (Fig. 2B).

\subsection{In vivo assay}

\subsubsection{Leaf wilting evaluation and stomatal conductance}

Leaf wilting at $120 \mathrm{dpi}$ in the resistant control clone Sapporo was low $(5.94 \% \pm 2.59$; mean $\pm \mathrm{SE})$, but high in the susceptible control clone M-PZ3 (68.33\% \pm 11.76$)$, confirming the virulence of the O. novo-ulmi isolate inoculated. Trees that were not inoculated with 0 . novo-ulmi (E-O- and $\mathrm{E}+\mathrm{O}-)$ showed no leaf yellowing or wilting symptoms, while trees inoculated with the pathogen $(\mathrm{E}-\mathrm{O}+$ and $\mathrm{E}+\mathrm{O}+)$ displayed various levels of leaf wilting. The four genotypes of the progeny (MCC1 $\times$ AL-AN1) exhibited a similar response to O. novo-ulmi $(P=0.423)$. Therefore, the effect of the genotype was not considered in subsequent analyses. Trees not inoculated with endophytes (E-O+) showed mean leaf wilting values of 48.93 to $66.95 \%$ at different evaluation dates (Fig. $3 \mathrm{~A}, \mathrm{C})$. Trees inoculated with $\mathrm{P} 5+\mathrm{YM} 11$ before 0 . novo-ulmi inoculation $(\mathrm{E}+\mathrm{O}+)$ showed similar symptoms to non-inoculated trees (E-O+) (Fig. 3A). In this case, the proportion of trees with leaf wilting percentages higher than $50 \%$ was similar in $\mathrm{E}-\mathrm{O}+$ and $\mathrm{E}+\mathrm{O}+$ plants at $120 \mathrm{dpi}$ (Fig. 3B). However, trees inoculated with $\mathrm{YCB} 36(\mathrm{E}+\mathrm{O}+)$ showed lower wilting symptoms than noninoculated trees (E-O+) at 30, 60 and 120 dpi (Fig. 3C). In this case, the proportion of trees with 
leaf wilting percentages higher than $50 \%$ was lower in $\mathrm{E}+\mathrm{O}+$ trees than in $\mathrm{E}-\mathrm{O}+$ trees at $120 \mathrm{dpi}$

(Fig. 3D). After 1 year, however, the protective effect of the YCB36 isolate was no longer evident

(Fig. 3C).

In addition, O. novo-ulmi inoculation caused a decline in stomatal conductance at $30 \mathrm{dpi}$, both in trees pre-inoculated with $\mathrm{P} 5+\mathrm{YM} 11(\mathrm{E}+\mathrm{O}+)$ (Fig. 4A, B) and E-O+ trees (Fig. 4a,b). YCB36inoculated trees (E+O-, Fig 4B) showed higher stomatal conductance at 30 dpi than noninoculated trees (E-O-, Fig. 4B).

\subsubsection{Endophyte presence estimation in planta}

At $75 \mathrm{dpi}$, P5 presence near the inoculation point was 4.81 times higher than in non-inoculated trees $(P<0.05)$. At $50 \mathrm{~cm}$, however, no significant differences were observed $(P>0.05)$. The estimated presence of YM11 in inoculated trees was 9.09 times higher than in non-inoculated trees at $50 \mathrm{~cm}$ from the inoculation point $(P<0.05)$ (Fig. 5A). YCB36 showed increased presence at both 5 and $50 \mathrm{~cm}$ above the inoculation point (4.64 and 17.86 times) $(P<0.05)$ (Fig. $5 \mathrm{~A})$. In all cases, amplification of ITS sequences in non-endophyte inoculated trees occurred in later cycles for YCB36 than for YM11 and P5, indicating a higher basal presence of P5 and YM11 than YCB36 in non-endophyte- inoculated elms.

One year after inoculation, endophyte presence estimation was typically lower than in $75 \mathrm{dpi}$ (Fig. 5B). P5 and YCB36 presence was still higher than in control plants at 50 and $5 \mathrm{~cm}$ from the inoculation point, respectively. Conversely, the presence of YM11 decreased to basal levels, showing no statistically significant differences with non-inoculated trees $(P>0.05)$.

\subsubsection{Biochemical changes induced in endophyte-inoculated trees}

Potential mechanisms of induced resistance were explored in YCB36-inoculated plants, as this was the only treatment that showed a protective effect against $O$. novo-ulmi in the trees. Soluble sugars and starch content in planta were not modified by endophyte inoculation $(P>0.15)$. However, both flavonoids and total phenols were significantly modified by YCB36 treatment. 
Flavonoid content was higher in YCB36- inoculated trees than in controls at $50 \mathrm{~cm}$ from the inoculation point $(P<0.05)$. Total phenols increased at both 5 and $50 \mathrm{~cm}$ from the inoculation point $(P<0.05)$ (Fig. 6A, B). Proline content significantly decreased in endophyte- inoculated trees at $50 \mathrm{~cm}$ above the inoculation point (Fig. 6C).

\section{Discussion}

\subsection{Phenotypic traits of the endophytic yeasts P5 and YM11}

According to the phenotypic traits of the endophytes, P5 (Cystobasidium) can be classified within the group of plant growth-promoting yeasts (Joubert and Doty, 2018) and YM11 (Exophiala) within the dark septate endophytes (DSE) (Andrade-Linares and Franken, 2013). Endophytic yeasts have been shown to stimulate plant growth, increase yield and reduce biotic or abiotic damage (Punja and Utkhede, 2003; Kandel et al., 2017; de Tenorio et al., 2019). Plant experiments performed with the pink yeast Rhodotorula spp. demonstrated increased phytoremediation ability (Silambarasan et al., 2019), strong inhibition of plant fungal or bacterial pathogens (Kalogiannis et al., 2006; Akhtyamova and Sattarova, 2013), increased plant germination rates (Akhtyamova and Sattarova, 2013) and increased root and shoot growth rates, mainly through their ability to synthesize phytohormones (Nutaratat et al., 2014; Sen et al., 2019). On the other hand, DSE comprise a polyphyletic group of non-mycorrhizal ascomycetous fungi with potentially beneficial functions for their host plants, such as reducing biotic and abiotic stresses (Jumpponen and Trappe, 1998; Andrade-Linares, 2011; Tellenbach et al., 2013) and improving plant performance by increasing $N$ and $P$ acquisition (He et al., 2019) or synthesizing or modifying phytohormone levels in planta (Schulz and Boyle, 2005; Wu et al., 2020). Plant studies on Exophiala spp. revealed their ability to increase host tolerance to abiotic stress by activating antioxidant enzymes (Khan et al., 2012) and improving plant growth through production of biologically active GAs (Khan et al., 2009). In our work, however, the Exophiala isolate (YM11) did not produce significant amounts of phytohormones and was the endophyte with the lowest $G A_{3}$ production, while P5 showed high production of IAA in the in vitro 
experiment (Fig. 3A). These results raise doubts about the role of YM11 as a producer of plant growth hormones, but support the classification of P5 as an IAA-producing yeast (Xin et al., 2009; Joubert and Doty, 2018). $\mathrm{GA}_{3}$ and IAA are the main hormones inducing cell proliferation and elongation, leading to enhanced root growth and stem elongation. Maintenance of high growth rates during 0 . novo-ulmi infection has been reported in small saplings as a resistance mechanism against the pathogen (Martín et al., 2019), and this mechanism could be enhanced in plants extensively colonized by hormone-producing yeasts. Although in the field assay the P5+YM11 treatment did not enhance tree resistance to DED, preliminary results with a similar P5+YM11 inoculum suggest that this treatment can induce root elongation (Martínez-Arias et al., unpublished results). Interestingly, YM11 and YCB36 were more inhibited than P5 by secondary metabolites that the tree might produce (Fig. 2), such as quercitin, cathechin, or gallic acid (Heimler et al. 1994; Martín et al., 2013). This suggests that P5 could be better adapted to grow under the chemical profile of elm wood.

Although both yeasts showed a weak inhibition of 0 . novo-ulmi, YM11 liquid filtrates were able to significantly reduce pathogen growth in liquid media, suggesting that inhibitory metabolites were secreted at a higher concentration in liquid culture than in solid medium.

\subsection{Inhibition mechanisms of $O$. novo-ulmi by endophyte YCB36}

YCB36 (Phaeosphaeriaceae) demonstrated strong in vitro antibiotic activity against $O$. novoulmi. The identity of this fungus at the species level using the ITS sequence is uncertain, but the most similar hits were found to be associated endophytically with a Quercus species (Moricca et al., 2012; Doust et al., 2017) (see NCBI accession numbers, Table 2). According to the LSU sequence, however, this strain can be tentatively assigned to Hydeomyces (Table 2). The activity of YCB36 against $O$. novo-ulmi in the in vitro dual culture assay evidenced strong pathogen inhibition without physical contact between mycelia, i.e. by antibiosis (Table 3; Fig. S2A, D ). YCB36 liquid exudates (evaluated in the antibiosis assay) exerted the highest inhibition of $O$. novo-ulmi, supporting the previous results and suggesting release of antibiotic metabolites into 
the culture medium (Table 3; Fig. S2C). The high hydrolytic activity of this endophyte may be involved in O. novo-ulmi growth inhibition. Both chitinolytic and proteolytic activities were highly positive in YCB36 (Table 3; Fig. S3), indicating that this fungus may have released these enzymes into the culture medium. Chitin is the major structural component of hyphal cell walls, and its enzymatic degradation via chitinases can disrupt or collapse fungal hyphae or even cause fungal death (Huang et al., 2007). For this reason, chitinolytic microorganisms have a potential application as biological control agents, as is the case with Trichoderma sp. (Aoki et al., 2020). In turn, proteases are usually needed to facilitate fungal entry into host tissues, and also play an important role in pathogen virulence during the entire infection cycle (Hueck, 1998; Figaj et al., 2019). In this experiment, as expected, the highest proteolytic activity was observed in $O$. novoulmi. This feature may give the pathogen an advantage over other fungi by enabling it to rapidly colonize elm xylem tissue. YCB36 also showed positive protease activity that could facilitate plant colonization and also affect O. novo-ulmi growth (Zhang et al., 2012).

Emission of antimicrobial VOCs by YCB36 may be another reason for the reduction in 0 . novoulmi growth. Several endophytic fungi have been reported to emit VOCs to establish a communicative interaction with their surroundings (Farre-Armengol et al., 2016; Roy and Banerjee, 2019). These molecules could have a potential role against fungal diseases due to their antimicrobial effects (Ezra et al., 2004; Chen et al., 2018; Wonglom et al., 2020) and/or ability to induce expression of defence genes in plants (Malmierca et al., 2012; Naznin et al., 2014; Pieterse et al., 2014). YCB36 showed the ability to reduce 0 . novo-ulmi growth when grown in confronted plates, probably through emission of volatile antibiotic molecules commonly attributed to terpenes, alcohols, and carboxylic acids (Zhang et al., 2014). Both chitinase and VOC emission by YCB36 could have a negative influence on $O$. novo-ulmi development in plant tissues and may have contributed to the reduced DED symptoms observed in YCB36- inoculated trees. Furthermore, a high nutritional niche overlap was observed between 0 . novo-ulmi and YCB36 in the nutrient utilization assay. Contrary to the results obtained by Blumenstein et al. 
(2015) with other elm endophytes, O. novo-ulmi and YCB36 showed the same range of metabolized carbon substrates, indicating a high nutritional niche overlap that could result in competitive interaction between endophyte and pathogen in planta. However, unlike YCB36, $O$. novo-ulmi is able to grow in the presence of certain inhibitory substances such as gallic acid and thymol, which could reflect its greater ability to cope with plant defensive metabolites.

Additionally, both 0 . novo-ulmi and YCB36 (in particular) displayed the ability to produce siderophores. Microorganisms use siderophores to obtain iron from the environment. In pathogenic interactions, they enable iron acquisition from host proteins and have an essential role in virulence in several plant pathogens (Oide et al., 2006; Chen et al., 2013; Albarouki et al., 2014). In mutualistic symbiotic relationships between plants and fungi, siderophores produced by the fungal symbiont facilitate plant access to natural insoluble iron found in soil, improving plant growth (Grobelak and Hiller, 2017). Many studies have also described the role of siderophores as stimulators of plant immunity (Buysens et al., 1996), in particular as activators of induced systemic resistance (ISR) (Beneduzi et al., 2012; Aznar and Dellagi, 2015), because they can be recognized as microbe-associated molecular patterns (MAMPs). Microbial geneknockout on siderophore emission revealed the importance of these molecules for ISR elicitation (De Vleesschauwer et al., 2008).

\subsection{Endophyte establishment and persistence in host tissues}

In the in vivo experiment, endophyte inoculations were performed for the first time on elm trees using the $B \mathrm{BIE}^{\circledR}$ endotherapy device. Fungal DNA amplification on $\mathrm{E}+\mathrm{O}$ - wood samples confirmed the success of the inoculation system, with inoculated trees showing higher P5, YM11 or YCB36 fungal presence than in non-inoculated trees (Fig. 5A, B). Nevertheless, the increased presence of these endophytes led to reduced symptoms after $O$. novo-ulmi inoculation only in YCB36inoculated trees (Fig. 3C). YCB36 showed a higher plant colonization rate than P5 and YM11 (Fig. $5 A, B$ ), possibly enhanced by its high protease activity. In the long term (one year after inoculation), however, the presence of YCB36 in plant tissue was markedly reduced, and the 
YCB36 isolate no longer exerted a protective effect (Fig. 5D), similar to what occurs in preventive inoculations with Verticillium albo-atrum in Ulmus sp. (Postma and Goossen-van de Geijn, 2016). In our case, despite the use of local elm endophytes, the elm fungal endobiome was resilient enough to reduce the presence of the artificially inoculated endophytes. This corroborates the assumption that the microbiome tends to be resistant and resilient to disturbances in community structure and has a composition that is very difficult to alter (Toju et al., 2018). The strength of microbiome communities seems to arise from pioneering fungi colonizing the seed or the plant at early plant developmental stages, when they are able to use space and resources and limit or slow down the establishment of later colonizers (Fukami et al., 2015, Wei et al., 2015;). Therefore, managing the microbiome at early developmental stages, i.e. before or during seed germination, using the targeted endophytes as early colonizers may be a worthwhile strategy for future experiments.

\subsection{Effects of YCB36 inoculation on tree physiology and defence metabolism}

Interestingly, YCB36- inoculated trees ( $\mathrm{E}+\mathrm{O}-$ ) showed increased leaf stomatal conductance (Fig. 4B), suggesting that this endophyte has the ability to modulate plant physiological functions. Several studies have highlighted the considerable influence of microbial symbionts on host water relations (Rho and Kim, 2017, and references therein). Stomatal conductance is positively related to photosynthetic $\mathrm{CO}_{2}$ uptake and, consequently, primary metabolism, which is involved in plant fitness and defence capability (Rosa et al., 2009). In this assay, no significant modifications in non-structural carbohydrates were observed, although we noticed a higher level of secondary metabolites (flavonoids and total phenolic content) in YCB36-inoculated trees than in non-inoculated trees (Fig. 6C, D). Phenolic compounds are widely distributed in plants and play key roles in metabolic and physiological processes (Boudet, 2007). These molecules also have antioxidant properties (Huang et al., 2007) that can ameliorate plant performance under stress conditions (Daayf et al., 2012; Cheynier et al., 2013; Mishra et al., 2018). Several studies have demonstrated increased synthesis of flavonoids and phenols in plants colonized by 
symbiotic microorganisms (Qawasmeh et al., 2012; Dupont et al., 2015). White et al. (2010) defended the hypothesis that enhanced production of antioxidants in endophyte-inoculated plants may be due to the plant response to endophyte-produced reactive oxygen species (ROS). Increased phenolic metabolites can also contribute to enhanced tree resistance to 0 . novo-ulmi in YCB36-inoculated trees, as reported in other elm studies (Witzell and Martín, 2008; Li et al., 2016). Moreover, accumulation of phenolic compounds may be linked to ISR activation. As described earlier, elm defence response could be triggered by YCB36 MAMPs, such as siderophores and VOCs. ISR activation is often regulated by a jasmonic/ethylene-dependent signalling pathway, and culminates with synthesis of pathogenesis-related proteins (PR proteins), synthesis of phytoalexins or, as observed in the YCB36-inoculated plants, accumulation of phenolic compounds (Conrath at al., 2002). Proline content reduction in YCB36inoculated trees may also indicate reduced tree stress. Lower proline levels have been described in various beneficial plant-microbe interactions, sometimes associated with better nutritional status and fitness and lower stress levels (Verslues and Sharma, 2010; Martínez-Arias et al., 2020).

Three different mechanisms may have contributed to the reduction in DED symptomatology in YCB36- inoculated trees: i) induction of plant resistance mechanisms that indirectly inhibit $O$. novo-ulmi development (ISR activation and phenolic accumulation); ii) $O$. novo-ulmi niche displacement by YCB36 due to nutritional overlap; and iii) direct inhibition of $O$. novo-ulmi by YCB36 through chitinase, antifungal metabolites, and VOC emissions. These mechanisms could act independently or synergistically. Examples include the symbiotic bacteria Pseudomonas aeruginosa, which is able to trigger ISR either through siderophore (Audenaert et al., 2002) or volatile emission (Ryu et al., 2004), and the Trichoderma biocontrol fungi, which have been shown to activate defence genes through $\mathrm{VOC}$ emission and inhibit pathogen growth by interacting with hydrolytic enzymes (Malmierca et al., 2012).

\section{Conclusions}


Our study provides new evidence for the role of fungal endophytes as alleviators of pathogen damages and for the mechanisms underlying this activity. YCB36, the endophytic fungus with highest antibiotic, protease, chitinase and siderophore activities in in vitro tests, significantly reduced DED symptomatology in the field test. Therefore, this endophyte is expected to be a promising candidate for development into a biological control agent to prevent or reduce DED damages. In contrast, although both endophytic yeasts were successfully established in elm stems after artificial inoculation into adult trees, neither Cystobasidium sp. (P5) nor Exophiala sp. (YM11) isolates alleviated wilting symptoms,

Further studies are needed to improve future field applications of YCB36 in elm trees. Because we observed a reduced YCB36 load one year after its application, annual or more frequent applications of the target endophyte could be necessary. Inoculation of YCB36 into elm seeds or in early developmental stages of vegetative reproductive materials (e.g., in vitro-propagated plants) could be another interesting strategy for producing plants colonized by the beneficial endophyte, since early plant colonizers have the advantage of using the space and resources earlier than subsequent competitors (priority effects). Moreover, similarly to the strategy followed by Miller et al. (2008), Tellenbach et al. (2013) or McMullin et al. (2018) for Phialocephala sp. endophytes, further information about the antibiotic molecules released by YCB36 in vitro is required to understand a mechanistic basis of YCB36 activity against DED. Additionally, more efficient protocols, including different inoculum densities and other inoculation methods, need to be examined to optimize treatments. Other elm clones and environmental conditions should be tested to validate the results, because previous research demonstrated the significance of these variables in the stability of tree protection against DED that some endophytes confer (Martín et al., 2015). Also, high-throughput methods for conidia production need to be examined to obtain mass quantities of cells, as conidia are the most resilient and suitable cell type used in formulations for biocontrol treatments (Mancera-López 
et al., 2019). Future experiments must be specifically planned to plan future large-scale application strategies.

\section{Acknowledgments}

We thank Jorge Dominguez, David Medel and David Macaya for assistance in plant propagation and endophyte isolation. This study was funded by the project GENESIS (AGL-2015-66952-R; MINECO/ERDF) and by an agreement for elm conservation between Universidad Politécnica de Madrid and Dirección General de Desarrollo Rural y Política Forestal (MAPA/EAFRD). C.M-A was supported by an FPI pre-doctoral fellowship from the Spanish Ministry of Economy and Competitiveness.

\section{References}

Agrawal T, Kotasthane AS. 2012. Chitinolytic assay of indigenous Trichoderma isolates collected from different geographical locations of Chhattisgarh in Central India. SpringerPlus 1 (1): 73.

Ainsworth EA, Gillespie KM. 2007. Estimation of total phenolic content and other oxidation substrates in plant tissues using Folin-Ciocalteu reagent. Nature Protocols 2(4): 875-877.

Akhtyamova N, Sattarova RK. 2013. Endophytic yeast Rhodotorula rubra Strain TG-1: Antagonistic and plant protection activities. Biochemistry and Physiology 2: 104. doi:10.4172/2168-9652.1000104

Albarouki E, Schafferer L, Ye F, von Wiren N, Haas H, Deising HB. 2014. Biotrophy-specific downregulation of siderophore biosynthesis in Colletotrichum graminicola is required for modulation of immune responses of maize. Molecular Microbiology 92(2): 338-355.

Andrade-Linares DR, Franken P. 2013. Fungal Endophytes in plant roots: Taxonomy, colonization patterns, and functions. Symbiotic Endophytes 37: 311-334.

Andrade-Linares DR, Grosch R, Restrepo S, Krumbein A, Franken P. 2011. Effects of dark septate endophytes on tomato plant performance. Mycorrhiza 21(5): 413-422.

Aoki Y, Haga S, Suzuki S. 2020. Direct antagonistic activity of chitinase produced 
by Trichoderma sp. SANA20 as biological control agent for grey mould caused by Botrytis cinerea. Cogent Biology 6:1, 1747903

Arnold AE, Mejia LC, Kyllo D, Rojas El, Maynard Z, Robbins N, Herre EA. 2003. Fungal endophytes limit pathogen damage in a tropical tree. Proceedings of the National Academy of Sciences of the United States of America 100(26): 15649-15654.

Audenaert K, Pattery T, Cornelis P, Hofte M. 2002. Induction of systemic resistance to Botrytis cinerea in tomato by Pseudomonas aeruginosa 7NSK2: role of salicylic acid, pyochelin, and pyocyanin. Molecular Plant Microbe Interactions 15(11): 1147-1156.

Aznar A, Dellagi A. 2015. New insights into the role of siderophores as triggers of plant immunity: what can we learn from animals? Journal of Experimental Botany 66(11): 3001-3010.

Barreira JCM, Ferreira ICFR, Oliveira MBPP, Pereira JA. 2008. Antioxidant activities of the extracts from chestnut flower, leaf, skins and fruit. Food Chemistry 107(3): 1106-1113.

Beneduzi A, Ambrosini A, Passaglia LMP. 2012. Plant growth-promoting rhizobacteria (PGPR): Their potential as antagonists and biocontrol agents. Genetics and Molecular Biology 35(4): 1044-1051.

Berríos J, Illanes A, Aroca G. 2004. Spectrophotometric method for determining gibberellic acid in fermentation broths. Biotechnology Letters 26(1): 67-70.

Blumenstein K, Albrectsen BR, Martín JA, Hultberg M, Sieber TN, Helander M, Witzell J. 2015. Nutritional niche overlap potentiates the use of endophytes in biocontrol of a tree disease. Biocontrol 60(5): 655-667.

Boudet AM. 2007. Evolution and current status of research in phenolic compounds. Phytochemistry 68(22-24): 2722-2735.

Brasier CM, Buck KW. 2001. Rapid evolutionary changes in a globally invading fungal pathogen (Dutch Elm Disease). Biological Invasions 3(3): 223-233.

Brasier CM, Lea J, Rawlings MK. 1981. The aggressive and non-aggressive strains of Ceratocystis ulmi have different temperature optima for growth. Transactions of the British 
Mycological Society 76(2): 213-218.

Brenner K, You LC, Arnold FH. 2008. Engineering microbial consortia: a new frontier in synthetic biology. Trends in Biotechnology 26(9): 483-489.

Buysens S, Heungens K, Poppe J, Hofte M. 1996. Involvement of pyochelin and pyoverdin in suppression of Pythium-induced damping-off of tomato by Pseudomonas aeruginosa 7NSK2. Applied and Environmental Microbiology 62(3): 865-871.

Carbone I, Kohn LM. 1999. A method for designing primer sets for speciation studies in filamentous ascomycetes. Mycologia 91 (3): 553-556.

Carillo P, Gibon Y. 2011. PROTOCOL: Extraction and determination of proline. PrometheusWiki. http://www.researchgate.net/publication/211353600_PROTOCOL_Extraction_and_de termination_of_proline

Carroll G. 1988. Fungal endophytes in stems and leaves - from latent pathogen to mutualistic symbiont. Ecology 69(1): 2-9.

Castro R, Álvarez A, Machado E, Mendoza M, Gómez R, García P. 2011. Characterization of an extracellular chitinase produced by Serratia sp. BIOMI-363706 using colloidal chitin as substrate. Revista de la Sociedad Química del Perú 77(2): 101-108.

Chamberlain K, Crawford DL. 1999. In vitro and in vivo antagonism of pathogenic turf grass fungi by Streptomyces hygroscopicus strains YCED9 and WYE53. Journal of Industrial Microbiology and Biotechnology 23(1): 641-646.

Chen LH, Lin CH, Chung KR. 2013. A nonribosomal peptide synthetase mediates siderophore production and virulence in the citrus fungal pathogen Alternaria alternata. Molecular Plant Pathology 14(5): 497-505.

Chen PH, Chen RY, Chou JY. 2018. Screening and evaluation of yeast antagonists for biological control of Botrytis cinerea on strawberry fruits. Mycobiology 46(1): 33-46.

Cheynier V, Comte G, Davies KM, Lattanzio V, Martens S. 2013. Plant phenolics: Recent advances on their biosynthesis, genetics, and ecophysiology. Plant Physiology and Biochemistry 72: 1-20. 
Conrath U, Pieterse C, Mauch-Mani B. 2002. Priming in plant-pathogen interactions. Trends in Plant Science 7(5): 210-216.

Daayf F, El Hadrami A, El-Bebany AE, Henriquez MA, Yao Z, Derksen H, El-Hadrami I, Adam LR. 2012. Phenolic compounds in plant defense and pathogen counter-defense mechanisms, in: Cheynier V, Sarni-Manchado P, Quideau S (eds) Recent Advances in Polyphenol Research. John Wiley \& Sons, Chichester, United Kingdom., pp. 191-208.

Dastogeer KMG, Li H, Sivasithamparam K, Jones MGK, Wylie SJ. 2018. Fungal endophytes and a virus confer drought tolerance to Nicotiana benthamiana plants through modulating osmolytes, antioxidant enzymes and expression of host drought responsive genes. Environmental and Experimental Botany 149: 95-108.

Della Monica IF, Saparrat MCN, Godeas AM and Scervino JM. 2015. The co-existence between DSE and AMF symbionts affects plant $P$ pools through $P$ mineralization and solubilization processes. Fungal Ecology 17:10-17.

de Tenorio DA, de Medeiros EV, Lima CS, da Silva JM, de Barros JA, Neves RP, Laranjeira D. 2019. Biological control of Rhizoctonia solani in cowpea plants using yeast. Tropical Plant Pathology 44(2): 113-119.

De Vleesschauwer D, Djavaheri M, Bakker PAHM, Hoefte M. 2008. Pseudomonas fluorescens WCS374r-induced systemic resistance in rice against Magnaporthe oryzae is based on pseudobactin-mediated priming for a salicylic acid-repressible multifaceted defense response. Plant Physiology 148(4): 1996-2012.

dos Reis Almeida BF, Cerqueira FM, Silva RdN, Ulhoa CJ, Lima AL. 2007. Mycoparasitism studies of Trichoderma harzianum strains against Rhizoctonia solani: Evaluation of coiling and hydrolytic enzyme production. Biotechnology Letters 29(8): 1189-1193.

Doty SL. 2011. Growth-Promoting Endophytic Fungi of Forest Trees, in: Pirttilä A., Frank A. (eds) Endophytes of Forest Trees Vol 80. Springer, Dordrecht, pp. 151-156.

Doust NH, Akbarinia M, Safaie N, Yousefzadeh H, Balint M. 2017. Community analysis of Persian oak fungal microbiome under dust storm conditions. Fungal Ecology 29: 1-9. 
Dupont P-Y, Eaton CJ, Wargent JJ, Fechtner S, Solomon P, Schmid J, Day RC, Scott B, Cox MP. 2015. Fungal endophyte infection of ryegrass reprograms host metabolism and alters development. New Phytologist 208(4): 1227-1240.

Ezra D, Hess WM, Strobel GA. 2004. New endophytic isolates of Muscodor albus, a volatileantibiotic-producing fungus. Microbiology-Sgm 150: 4023-4031.

Fakhro A, Andrade-Linares DR, von Bargen S, Bandte M, Buettner C, Grosch R, Schwarz D, Franken P. 2010. Impact of Piriformospora indica on tomato growth and on interaction with fungal and viral pathogens. Mycorrhiza 20(3): 191-200.

Farre-Armengol G, Filella I, Llusia J, Penuelas J. 2016. Bidirectional interaction between phyllospheric microbiotas and plant volatile emissions. Trends in Plant Science 21(10): 854-860.

Fesel PH, Zuccaro A. 2016. Dissecting endophytic lifestyle along the parasitism/mutualism continuum in Arabidopsis. Current Opinion in Microbiology 32: 103-112.

Figaj D, Ambroziak P, Przepiora T, Skorko-Glonek J. 2019. The role of proteases in the virulence of plant pathogenic bacteria. International Journal of Molecular Sciences 20(3): 672.

Frasz S, Walker AK, Nsiama TK, Adams GW, Miller JD. 2014. Distribution of the foliar fungal endophyte Phialocephala scopiformis and its toxin in the crown of a mature white spruce tree as revealed by chemical and qPCR analyses. Canadian Journal of Forest Research 44: 1138-1143.

Fukami T. 2015. Historical contingency in community assembly: Integrating niches, species pools, and priority effects. Annual Review of Ecology, Evolution, and Systematics. 46: 123.

Gang S, Sharma S, Saraf M, Buck M, Schumacher J. 2019. Analysis of Indole-3-acetic Acid (IAA) Production in Klebsiella by LC-MS/MS and the Salkowski Method. Bio-Protoco/ 9(9).

Gibb EA, Hausner G. 2005. Optional mitochondrial introns and evidence for a homingendonuclease gene in the mtDNA rnl gene in Ophiostoma ulmi s. lat. Mycological Research 109: 1112-1126. 
Glass NL, Donaldson G C. 1995. Development of primer sets designed for use with the PCR to amplify conserved genes from filamentous ascomycetes. Applied and environmental microbiology 61(4): 1323-1330.

Grobelak A, Hiller J. 2017. Bacterial siderophores promote plant growth: Screening of catechol and hydroxamate siderophores. International Journal of Phytoremediation 19(9): 825833.

Guthrie JL, Castle AJ. 2006. Chitinase production during interaction of Trichoderma aggressivum and Agaricus bisporus. Canadian Journal of Microbiology 52(10): 961-967.

Haas D, Defago G. 2005. Biological control of soil-borne pathogens by fluorescent pseudomonas. Nature Reviews Microbiology 3(4): 307-319.

Halecker S, Wennrich JP, Rodrigo S, Andrée N, Rabsch L, Baschien C, Steinert M, Stadler M, Surup F, Schulz B. 2020. Fungal endophytes for biocontrol of ash dieback: the antagonistic potential of Hypoxylon rubiginosum. Fungal Ecology. 45: 100918

Hardoim PR, van Overbeek LS, Berg G, Pirttila AM, Compant S, Campisano A, Doring M, Sessitsch A. 2015. The hidden world within plants: Ecological and evolutionary considerations for defining functioning of microbial endophytes. Microbiology and Molecular Biology Reviews 79(3): 293-320.

Haselwandter K, Winkelmann G. 2007. Siderophores of symbiotic fungi in: Varma A, Chincholkar SB (eds.) Microbial Siderophores. Springer, Berlin Heidelberg, pp. 91-103.

Haselwandter K, Haas H, Haninger G, Winkelmann G. 2020. Siderophores in plant root tissue: Tagetes patula nana colonized by the arbuscular mycorrhizal fungus Gigaspora margarita. BioMetals. https://doi.org/10.1007/s10534-020-00238-0

He C, Wang W, Hou J. 2019. Characterization of dark septate endophytic fungi and improve the performance of liquorice under organic residue treatment. Frontiers in Microbiology. 10: 1364

Heimler D, Pieroni A, Mittempergher L. 1996. Plant phenolics in elms (Ulmus spp.) infected by Dutch elm disease fungus (Ophiostoma ulmi). Acta Horticulturae 381: 87. 
https://doi.org/10.17660/ActaHortic.1994.381.87

Holbrook AA, Edge WJW, Bailey P. 1961. Spectrophotometric method for determination of gibberellic acid. Advances in Chemistry 28: 159-167.

Huang WY, Cai YZ, Xing J, Corke H, Sun M. 2007. A potential antioxidant resource: Endophytic fungi from medicinal plants. Economic Botany 61(1): 14-30.

Hueck CJ. 1998. Type III protein secretion systems in bacterial pathogens of animals and plants. Microbiology and Molecular Biology Reviews 62(2): 379-433.

Joubert PM, Doty SL. 2018. Endophytic Yeasts: Biology, Ecology and Applications in: Pirttilä A., Frank A. (eds) Endophytes of Forest Trees: Biology and Applications Vol. 86. Springer, Cham, pp.3-14.

Jumpponen A, Trappe JM. 1998. Dark septate endophytes: a review of facultative biotrophic root-colonizing fungi. New Phytologist 140(2): 295-310.

Kalogiannis S, Tjamos SE, Stergiou A, Antoniou PP, Ziogas BN, Tjamos EC. 2006. Selection and evaluation of phyllosphere yeasts as biocontrol agents against grey mould of tomato. European Journal of Plant Pathology 116(1): 69-76.

Kandel SL, Firrincieli A, Joubert PM, Okubara PA, Leston ND, McGeorge KM, Mugnozza GS, Harfouche A, Kim SH, Doty SL. 2017. An In vitro study of bio-control and plant growth promotion potential of Salicaceae endophytes. Frontiers in Microbiology 8: 16.

Khan AL, Hamayun M, Kang S-M, Kim Y-H, Jung H-Y, Lee J-H, Lee I-J. 2012. Endophytic fungal association via gibberellins and indole acetic acid can improve plant growth under abiotic stress: an example of Paecilomyces formosus LHL10. Bmc Microbiology 12: 3.

Khan SA, Hamayun M, Kim H-Y, Yoon H-J, Lee I-J, Kim J-G. 2009. Gibberellin production and plant growth promotion by a newly isolated strain of Gliomastix murorum. World Journal of Microbiology and Biotechnology 25(5): 829-833.

Khare E, Mishra J, Arora NK. 2018. Multifaceted interactions between endophytes and plant: developments and prospects. Frontiers in Microbiology 9: 2732.

Kusari P, Kusari S, Spiteller M, Kayser O. 2013. Endophytic fungi harbored in Cannabis sativa L.: 
diversity and potential as biocontrol agents against host plant-specific phytopathogens.

Fungal Diversity 60(1): 137-151.

Lata R, Chowdhury S, Gond SK, White JF Jr. 2018. Induction of abiotic stress tolerance in plants by endophytic microbes. Letters in Applied Microbiology 66(4): 268-276.

Lau JA, Lennon JT, Heath KD. 2017. Trees harness the power of microbes to survive climate change. Proceedings of the National Academy of Sciences of the United States of America 114: $11009-11011$.

Laurentin A, Edwards CA. 2003. A microtiter modification of the anthrone-sulfuric acid colorimetric assay for glucose-based carbohydrates. Analytical Biochemistry 315(1): 143-145.

Lee HB, Magan N. 1999. Environmental factors and nutritional utilization patterns affect niche overlap indices between Aspergillus ochraceus and other spoilage fungi. Letters in Applied Microbiology 28(4): 300-304.

Li M, López R, Venturas M, Martín JA, Domínguez J, González-Gordaliza G, Gil L,RodríguezCalcerrada J. 2016. Physiological and biochemical differences among Ulmus minor genotypes showing a gradient of resistance to Dutch elm disease. Forest Pathology. 46(3):215-228.

Malmierca MG, Cardoza RE, Alexander NJ, McCormick SP, Hermosa R, Monte E, Gutierrez S. 2012. Involvement of Trichoderma trichothecenes in the biocontrol activity and induction of plant defense-related genes. Applied and Environmental Microbiology 78(14): 4856-4868.

Mancera-López ME, Izquierdo-Estevez WF, Escalante-Sanchez A, Ibarra JE, Barrera-Cortes J. 2019. Encapsulation of Trichoderma harzianum conidia as a method of conidia preservation at room temperature and propagation in submerged culture. Biocontrol Science and Technology 29(2): 107-130.

Maness N 2010. Extraction and analysis of soluble carbohydrates in: Sunkar R (ed.) Plant Stress Tolerance: Methods and Protocols. Humana Press Inc, Totowa, pp. 341-370. 
Macaya-Sanz D, Witzell J, Collada C, Gil L, Martin JA. 2020. Structure of core fungal endobiome in Ulmus minor: patterns within the tree and across genotypes differing in tolerance to Dutch elm disease. bioRxivhttps://doi.org/10.1101/2020.06.23.166454

Martín JA, Macaya-Sanz D, Witzell J, Blumenstein K, Gil L. 2015. Strong in vitro antagonism by elm xylem endophytes is not accompanied by temporally stable in planta protection against a vascular pathogen under field conditions. European Journal of Plant Pathology 142(1): 185-196.

Martín JA, Solla A, Witzell J, Gil L, Garcia-Vallejo MC. 2010. Antifungal effect and reduction of Ulmus minor symptoms to Ophiostoma novo-ulmi by carvacrol and salicylic acid. European Journal of Plant Pathology 127(1): 21-32.

Martín JA, Witzell J, Blumenstein K, Rozpedowska E, Helander M, Sieber TN, Gil L. 2013. Resistance to Dutch Elm Disease reduces presence of xylem endophytic fungi in elms (Ulmus spp.). Plos One 8(2): 13.

Martín JA, Macaya-Sanz D, Witzell J, Blumenstein K, Gil L. 2015. Strong in vitro antagonism by elm xylem endophytes is not accompanied by temporally stable in planta protection against a vascular pathogen under field conditions. European Journal of Plant Pathology 142: $185-196$.

Martín JA, Sobrino-Plata J, Rodríguez-Calcerrada J, Collada C, Gil L. 2019. Breeding and scientific advances in the fight against Dutch elm disease: Will they allow the use of elms in forest restoration? New Forests 50(2): 183-215.

Martínez-Álvarez P, Arcadio Fernández-González R, Sanz-Ros VA, Pando V, Diez JJ. 2016. Two fungal endophytes reduce the severity of pitch canker disease in Pinus radiata seedlings. Biological Control 94: 1-10.

Martínez-Arias C, Macaya-Sanz D, Witzell J, Martín JA. 2019. Enhancement of Populus alba tolerance to Venturia tremulae upon inoculation with endophytes showing in vitro biocontrol potential. European Journal of Plant Pathology 153(4): 1031-1042.

Martínez-Arias C, Sobrino-Plata J, Macaya-Sanz D, Aguirre NM, Collada C, Gil L, Martín JA, 
Rodríguez-Calcerrada J. 2020. Changes in plant function and root mycobiome caused by flood and drought in a riparian tree. Tree Physiology 40(7): 886-903.

Martínez-Medina A, Appels FVW, van Wees SCM. 2017. Impact of salicylic acid- and jasmonic acid- regulated defences on root colonization by Trichoderma harzianum T-78. Plant Signaling and Behaviour 12(8): e1345404

Mayerhofer HJ, Marshall RT, White CH, Lu M. 1973. Characterization of a heat-stable protease of Pseudomonas fluorescens P26. Applied Microbiology 25(1): 44-48.

McMullin DR, NguyenHDT, Daly GJ, Menard BS and Miller JD. 2018. Detection of foliar endophytes and their metabolites in Picea and Pinus seedling needles. Fungal Ecology 31:1-8.

Mejía LC, Rojas El, Maynard Z, Van Bael S, Arnold AE, Hebbar P, Samuels GJ, Robbins N, Herre EA. 2008. Endophytic fungi as biocontrol agents of Theobroma cacao pathogens. Biological Control 46(1): 4-14.

Millar RL, Higgins VJ. 1970. Association of cyanide with infection of birdsfoot trefoil by Stemphylium loti. Phytopathology 60(1): 104-110.

Miller JD, Sumarah MW, Adams GW. 2008. Effect of a rugulosin-producing endophyte in Picea glauca on Choristoneura fumiferana. Journal of Chemical Ecology 34: 362-368.

Mishra A, Singh SP, Mahfooz S, Singh SP, Bhattacharya A, Mishra N, Nautiyal CS. 2018. Endophyte-mediated modulation of defense-related genes and systemic resistance in Withania somnifera (L.) dunal under Alternaria alternate stress. Applied and Environmental Microbiology 84(8): e02845-02817.

Moricca S, Ginetti B, Ragazzi A. 2012. Species- and organ-specificity in endophytes colonizing healthy and declining Mediterranean oaks. Phytopathologia Mediterranea 51(3): 587598.

Moller L, Lerm B, Botha A. 2016. Interactions of arboreal yeast endophytes: an unexplored discipline. Fungal Ecology 22:73-82.

Naidoo S, Slippers B, Plett JM, Coles D, Oates CN. 2019. The road to resistance in forest trees. 
Frontiers in Plant Science 10: 273.

Naznin HA, Kiyohara D, Kimura M, Miyazawa M, Shimizu M, Hyakumachi M. 2014. Systemic resistance induced by volatile organic compounds emitted by plant growth-promoting fungi in Arabidopsis thaliana. Plos One 9(1): e86882.

Nutaratat P, Srisuk N, Arunrattiyakorn P, Limtong S. 2014. Plant growth-promoting traits of epiphytic and endophytic yeasts isolated from rice and sugar cane leaves in Thailand. Fungal Biology 118(8): 683-694.

Oide S, Moeder W, Krasnoff S, Gibson D, Haas H, Yoshioka K, Turgeon BG. 2006. NPS6, encoding a non-ribosomal peptide synthetase involved in siderophore-mediated iron metabolism, is a conserved virulence determinant of plant pathogenic ascomycetes. Plant Cell 18(10): 2836-2853.

Orlandelli RC, de Almeida TT, Alberto RN, Polonio JC, Azevedo JL, Pamphile JA. 2015. Antifungal and proteolytic activities of endophytic fungi isolated from Piper hispidum Sw. Brazilian Journal of Microbiology 46(2): 359-366.

Patten CL, Glick BR. 2002. Role of Pseudomonas putida indole-acetic acid in development of the host plant root system. Applied and Environmental Microbiology 68(8): 3795-3801.

Pieterse CMJ, Zamioudis C, Berendsen RL, Weller DM, Van Wees SCM, Bakker P. 2014. Induced systemic resistance by beneficial microbes. Annual Review of Phytopathology52: 347375.

Postma J, Goossen-van de Geijn H. 2016. Twenty-four years of Dutch Trig(R) application to control Dutch elm disease. Biocontrol 61(3): 305-312.

Priyadharsini P, Muthukumar T. 2017. The root endophytic fungus Curvularia geniculata from Parthenium hysterophorus roots improves plant growth through phosphate solubilization and phytohormone production. Fungal Ecology 27: 69-77.

Punja ZK, Utkhede RS. 2003. Using fungi and yeasts to manage vegetable crop diseases. Trends in Biotechnology 21(9): 400-407. 
Qawasmeh A, Obied HK, Raman A, Wheatley W. 2012. Influence of fungal endophyte infection on phenolic content and antioxidant activity in grasses: Interaction between Lolium perenne and different strains of Neotyphodium Iolii. Journal of Agricultural and Food Chemistry 60(13): 3381-3388.

Quiring D, Flaherty L, Adams G, McCartney A, Miller D, Edwards S. 2019. An endophytic fungus interacts with crown level and larval density to reduce the survival of eastern spruce budworm, Choristoneura fumiferana (Lepidoptera: Tortricidae), on white spruce (Picea glauca). Canadian Journal of Forest Research 49: 221-227.

Rabiey M, Hailey LE, Roy SR, Grenz K, Al-Zadjali MAS, Barret GA, Jackson RW. 2019. Endophytes vs tree pathogens and pests: can they be used as biological control agents to improve tree health? European Journal of Plant Pathology 155: 711-729.

Rho T, Kim SH. 2017. Endophyte effects on photosynthesis and water use of plant hosts: A metaanalysis, in: Doty S. (ed),Functional Importance of the Plant Microbiome: Implications for Agriculture, Forestry and Bioenergy. Springer, Cham, pp.43-69.

Richardson SN, Nsiama TK, Walker AK, McMullin DR, Miller JD. 2015. Antimicrobial dihydrobenzofurans and xanthenes from a foliar endophyte of Pinus strobus. Phytochemistry 117: 436-443.

Rijavec T, Lapanje A. 2016. Hydrogen cyanide in the rhizosphere: not suppressing plant pathogens, but rather regulating availability of phosphate. Frontiers in Microbiology 7: 1785.

Rodríguez RJ, White JF Jr., Arnold AE, Redman RS. 2009. Fungal endophytes: diversity and functional roles. New Phytologist 182(2): 314-330.

Rosa M, Prado C, Podazza G, Interdonato R, Gonzalez JA, Hilal M, Prado FE. 2009. Soluble sugars metabolism, sensing and abiotic stress. A complex network in the life of plants. Plant Signaling and Behavior 4(5): 388-393.

Roy S, Banerjee D. 2019. Volatile organic compounds from endophytic fungi, in: Yadav A., Singh 
S., Mishra S., Gupta A. (eds) Recent Advancement in White Biotechnology through Fungi. Springer, Cham, pp. 149-175.

Ryu CM, Farag MA, Hu CH, Reddy MS, Kloepper JW, Pare PW. 2004. Bacterial volatiles induce systemic resistance in Arabidopsis. Plant Physiology 134(3): 1017-1026.

Scheffer RJ. 1990. Mechanisms involved in biological control of Dutch Elm Disease. Journal of Phytopathology-Phytopathologische Zeitschrift 130(4): 265-276.

Schulz B, Wanke U, Draeger H, Aust HJ. 1993. Endophytes from herbaceous plants and shrubs: effectiveness of surface sterilization. Mycological Research 97: 1447-1450.

Schulz B, Boyle C. 2005. The endophytic continuum. Mycological Research 109: 661-686.

Schwyn B, Neilands JB. 1987. Universal chemical assay for the detection and determination of siderophores. Analytical Biochemistry 160(1): 47-56.

Sen D, Paul K, Saha C, Mukherjee G, Nag M, Ghosh S, Das A, Seal A, Tripathy S. 2019. A unique life-strategy of an endophytic yeast Rhodotorula mucilaginosa JGTA-S1-a comparative genomics viewpoint. DNA Research 26(2): 131-146.

Shi Y, Lou K, Li C. 2009. Promotion of plant growth by phytohormone-producing endophytic microbes of sugar beet. Biology and Fertility of Soils 45(6): 645-653.

Silambarasan S, Logeswari P, Cornejo P, Abraham J, Valentine A. 2019. Simultaneous mitigation of aluminum, salinity and drought stress in Lactuca sativa growth via formulated plant growth promoting Rhodotorula mucilaginosa CAM4. Ecotoxicology and Environmental Safety 180: 63-72.

Singh LP, Gill SS, Tuteja N. 2011. Unraveling the role of fungal symbionts in plant abiotic stress tolerance. Plant Signaling and Behavior 6: 175-191.

Stielow JB, Lévesque CA, Seifert KA., Meyer W, Iriny, L, Smits D, Renfurm R, Verkley GJ, Groenewald M, Chaduli D, Lomascolo A, Welti S, Lesage-Meessen L, Favel A, Al-Hatmi A M, Damm U, Yilmaz N, Houbraken J, Lombard L, Quaedvlieg W, et al. 2015. One fungus, which genes? Development and assessment of universal primers for potential secondary fungal DNA barcodes. Persoonia 35: 242-263. 
Solla A, Gil L. 2003. Evaluating Verticillium dahliae for biological control of Ophiostoma novoulmi in Ulmus minor. Plant Pathology 52(5): 579-585.

Solla A, Martín JA, Ouellette GB, Gil L. 2005. Influence of plant age on symptom development in Ulmus minor following inoculation by Ophiostoma novo-ulmi. Plant Disease 89(10): 1035-1040.

Shoresh M, Harman GE, Mastouri F. 2010. Induced Systemic Resistance and Plant Responses to Fungal Biocontrol Agents. Annual Review of Phytopathology 2010 48: 21-43.

Surono and Narisawa K. 2017. The dark septate endophytic fungus Phialocephala fortinii is a potential decomposer of soil organic compounds and a promoter of Asparagus officinalis growth. Fungal Ecology 28: 1-10.

Tanney JB, Renaud JB, Miller JD, McMullin DR. 2018. New 1,3-benzodioxin-4-ones from Synnemapestaloides ericacearum sp. nov., a biosynthetic link to remarkable compounds within the Xylariales. Plos One 13(6): e0198321

Tchernoff V. 1965. Methods for screening and for the rapid selection of elms for resistance to Dutch Elm Disease. Acta Botanica Neerlandica 14(4): 409-452.

Tellenbach C, Sumarah MW, Grünig CR, Miller JD. 2013. Inhibition of Phytophthora species by secondary metabolites produced by the dark septate endophyte Phialocephala europaea. Fungal Ecology 6: 12-18.

Terhonen E, Blumenstein K, Kovalchuk A, Asiegbu FO. 2019. Forest Tree Microbiomes and Associated Fungal Endophytes: Functional Roles and Impact on Forest Health. Forests 10: 42 .

Toju H, Peay KG, Yamamichi M, Narisawa K, Hiruma K, Naito K, Fukuda S, Ushio M, Nakaoka S, Onoda Y, et al. 2018. Core microbiomes for sustainable agroecosystems. Nature Plants 4(5): 247-257.

Udvardi MK, Czechowski T, Scheible W-R. 2008. Eleven golden rules of quantitative RT-PCR. Plant Cell 20(7): 1736-1737.

Vandenkoornhuyse P, Quaiser A, Duhamel M, Le Van A, Dufresne A. 2015. The importance of 
the microbiome of the plant holobiont. New Phytologist, 206: 1196-1206.

Verslues PE, Sharma S. 2010. Proline metabolism and its implications for plant-environment interaction. The arabidopsis book/American Society of Plant Biologists 8: e0140.

Videira SS, de Oliveira DM, de Morais RF, Borges WL, Divan Baldani VL, Baldani JI. 2012. Genetic diversity and plant growth promoting traits of diazotrophic bacteria isolated from two Pennisetum purpureum Schum. genotypes grown in the field. Plant and Soil 356(1-2): 51-66.

Vilgalys R, Hester M. 1990. Rapid genetic identification and mapping of enzymatically amplified ribosomal DNA from several Cryptococcus species. Journal of Bacteriology 172: 42384246.

Wei Z, Yang TJ, Friman VP, Xu YC, Shen QR, Jousset A. 2015. Trophic network architecture of root-associated bacterial communities determines pathogen invasion and plant health. Nature Communications 6: 8417.

White JF, Jr., Torres MS. 2010. Is plant endophyte-mediated defensive mutualism the result of oxidative stress protection? Physiologia Plantarum 138(4): 440-446.

White TJ, Bruns T, Lee S, Taylor JW 1990. Amplification and direct sequencing of fungal ribosomal RNA genes for phylogenetics. PCR protocols: A guide to methods and applications. New York, 315-322.

Witzell J, Martín JA. 2008. Phenolic metabolites in the resistance of northern forest trees to pathogens - past experiences and future prospects. Canadian Journal of Forest Research-Revue Canadienne De Recherche Forestière 38(11): 2711-2727.

Witzell J, Martín JA. 2018. Endophytes and Forest Health, in: Pirttilä A., Frank A. (eds) Endophytes of Forest Trees: Biology and Applications, 2nd Edition vol. 86. Springer, Cham, pp. 261-282.

Wonglom P, Ito S, Sunpapao A. 2020. Volatile organic compounds emitted from endophytic fungus Trichoderma asperellum T1 mediate antifungal activity, defense response and promote plant growth in lettuce (Lactuca sativa). Fungal Ecology 43: 100867 
Wu FL, Li Y, Tian W, Sun Y, Chen F, Zhang Y, Zhai Y, Zhang J, Su H, Wang L. 2020. A novel dark septate fungal endophyte positively affected blueberry growth and changed the expression of plant genes involved in phytohormone and flavonoid biosynthesis. Tree Physiology, tpaa047, https://doi.org/10.1093/treephys/tpaa047

Xin G, Glawe D, Doty SL. 2009. Characterization of three endophytic, indole-3-acetic acidproducing yeasts occurring in Populus trees. Mycological Research 113: 973-980.

Yang MZ, Ma MD, Yuan MQ, Huang ZY, Yang WX, Zhang HB, Huang LH, Ren AY, Shan H. 2016. Fungal endophytes as a metabolic fine-tuning regulator for wine grape. Plos One 11(9).

Zhang D, Spadaro D, Valente S, Garibaldi A, Gullino ML. 2012. Cloning, characterization, expression and antifungal activity of an alkaline serine protease of Aureobasidium pullulans PL5 involved in the biological control of postharvest pathogens. International Journal of Food Microbiology 153(3): 453-464.

Zhang F, Yang X, Ran W, Shen Q. 2014. Fusarium oxysporum induces the production of proteins and volatile organic compounds by Trichoderma harzianum T-E5. Fems Microbiology Letters 359(1): 116-123.

\section{Figure legends}

Fig. 1: Two-joining clustering analysis of the in-house configured phenotypic arrays of fungal endophytes and $O$. novo-ulmi (horizontal axis) growing with different nutrients and inhibitory substrates (vertical axis). Euclidean distances were used in the clustering of fungal endophytes and substrates. The colour legend indicates inhibition (bluish colours) or promotion (reddish colours) of fungal growth.

Fig. 2: Indole-3-acetic acid (IAA) and gibberellic acid $\left(\mathrm{GA}_{3}\right)$ production by fungal endophytes and pathogen. (A) IAA production by $O$. novo-ulmi and fungal endophytes (YCB36, P5 and YM11) after 15 days of incubation in malt extract broth containing $0.2 \%$ L-tryptophan. (B) $\mathrm{GA}_{3}$ content in liquid filtrates after which $O$. novo-ulmi and the three endophytes have been growing in YMG for 40 days. Different letters indicate significant differences between fungi according to Fisher's post-hoc test $(P<0.05)$.

Fig. 3: Leaf wilting induced by 0 . novo-ulmi inoculation at 30, 60, $120 \mathrm{dpi}$ and 1 ypi in: P5+YM11inoculated trees (A), and YCB36-inoculated trees (C). The proportion of trees with leaf wilting percentages higher or lower than $50 \%$ is shown in (B) for P5+YM11-inoculation and in (D) for YCB36-inoculation. $\mathrm{E}-\mathrm{O}+$ indicates non-endophyte-inoculated trees with $\mathrm{O}$. novo-ulmi inoculation, and $\mathrm{E}+\mathrm{O}+$ indicates endophyte-inoculated trees with $\mathrm{O}$. novo-ulmi inoculation. Non- 
O. novo-ulmi-inoculated trees (not shown) showed no wilting symptoms. Asterisks in graphs (A) and $(B)$ indicate significant differences between treatments according to Fisher's post-hoc test $(\mathrm{P}<0.05)$.

Fig. 4: Stomatal conductance measured at $0 \mathrm{dpi}$ and $30 \mathrm{dpi}$ in P5 + YM11-inoculated plants (A) and YCB36-inoculated plants (B). Treatments were: trees without endophyte or O. novo-ulmi inoculation (E-O-); non-endophyte-inoculated trees with $\mathrm{O}$. novo-ulmi inoculation (E-O+); endophyte-inoculated trees without $O$. novo-ulmi inoculation ( $\mathrm{E}+\mathrm{O}-)$, and trees inoculated with endophyte before $O$. novo-ulmi inoculation $(\mathrm{E}+\mathrm{O}+)$. Different letters indicate significant differences between treatments according to Fisher's post-hoc test $(P<0.05)$.

Fig. 5: Relative presence of fungal endophytes estimated by qPCR at $75 \mathrm{dpi}$ (A) and 1 ypi (B) in P5+YM11-inoculated trees (left panel) and YCB36 inoculated trees (right panel). Quantifications were performed at 5 and $50 \mathrm{~cm}$ above the endophyte inoculation point. Results are shown as a fold change of presence in non-endophyte inoculated trees (E-O-). Asterisks indicate significant differences to $\mathrm{E}-\mathrm{O}$ - trees according to Fisher's post-hoc test $(\mathrm{P}<0.05)$.

Fig. 6: Biochemical measurements in wood samples of YCB36-inoculated and control trees at 5 and $50 \mathrm{~cm}$ from the inoculation point and at $75 \mathrm{dpi}$. (A) Total flavonoid content; (B) total phenolic content and $(C)$ proline content. Different letters in the graphs indicate significant differences between YCB36-inoculated and non-inoculated trees at $5 \mathrm{~cm}$ (normal letters) and 50 $\mathrm{cm}$ (italics) according to Fisher's post-hoc test $(P<0.05)$.

Fig. S1: Experimental procedure. First, a fungal cell suspension was inoculated into the vascular system at the trunk base using an endotherapy device. O. novo-ulmi inoculations were performed 15 days later using a spore suspension following traditional inoculation methods for DED. Four treatments were applied for each endophyte combination (P5+YM11 or YCB36): E+O: endophyte-inoculated plants without $O$. novo-ulmi inoculation, E-O+: O. novo-ulmi-inoculated plants without previous endophyte inoculation, $\mathrm{E}+\mathrm{O}+$ : endophyte and $\mathrm{O}$. novo-ulmi-inoculated plants, and E-O-: non-inoculated plants (neither endophyte nor $O$. novo-ulmi). Leaf wilting was evaluated in each tree at 30,60, 120 days post (pathogen) inoculation (dpi) and 1 year postinoculation (ypi) by three independent assessors. At $75 \mathrm{dpi}$ a wood sample was cored with an increment borer $(\mathrm{N}=3)$ at 5 and $50 \mathrm{~cm}$ above the inoculation point for biochemical and fungal quantification measures. $\mathrm{SS}=$ soluble sugars.

Fig. S2: In vitro interactions between $O$. novo-ulmi and fungal endophytes. (A) O. novo-ulmi growth when confronted with fungal endophytes in dual late assays; (B) O. novo-ulmi growth when confronted with fungal endophytes in petri dishes to evaluate the effect of endophyte volatile substances (VOCs) emission; (C) O. novo-ulmi growth in the presence of endophyte liquid filtrates in 96-well microplates. In (C) $O$. novo-ulmi growth is measured by optical density (OD). Asterisks indicate statistically significant differences to the control treatment according to Fisher's post-hoc test $(P<0.05)$. Dual culture and VOC assay illustrations $(D)$. In the dual culture, $O$. novo-ulmi (white colony at the left side of the plate) is confronted with fungal endophytes (YCB36, P5 and YM11) (right side of the plate) at day 12. The VOCs assay shows the results of $O$. novo-ulmi growth in the presence of endophytes in confronted plates at day 10 . The scale bar below each petri dish indicates a length of $1 \mathrm{~cm}$.

Fig. S3: Protease and chitinase activities and siderophore production in in vitro assays performed by fungal endophytes and pathogen at day 20 . Dotted red line delimits colony diameter; dotted yellow line delimits clear halo diameter. Chitinase activity and siderophore production were negative (NA) for endophytes P5 and YM11. The scale bar below each petri dish indicates a length of $1 \mathrm{~cm}$. 
bioRxiv preprint doi: https://doi.org/10.1101/2020.05.04.076349; this version posted September 15, 2020. The copyright holder for this preprint (which was not certified by peer review) is the author/funder, who has granted bioRxiv a license to display the preprint in perpetuity. It is made available under aCC-BY-NC-ND 4.0 International license. 
Fig. 1

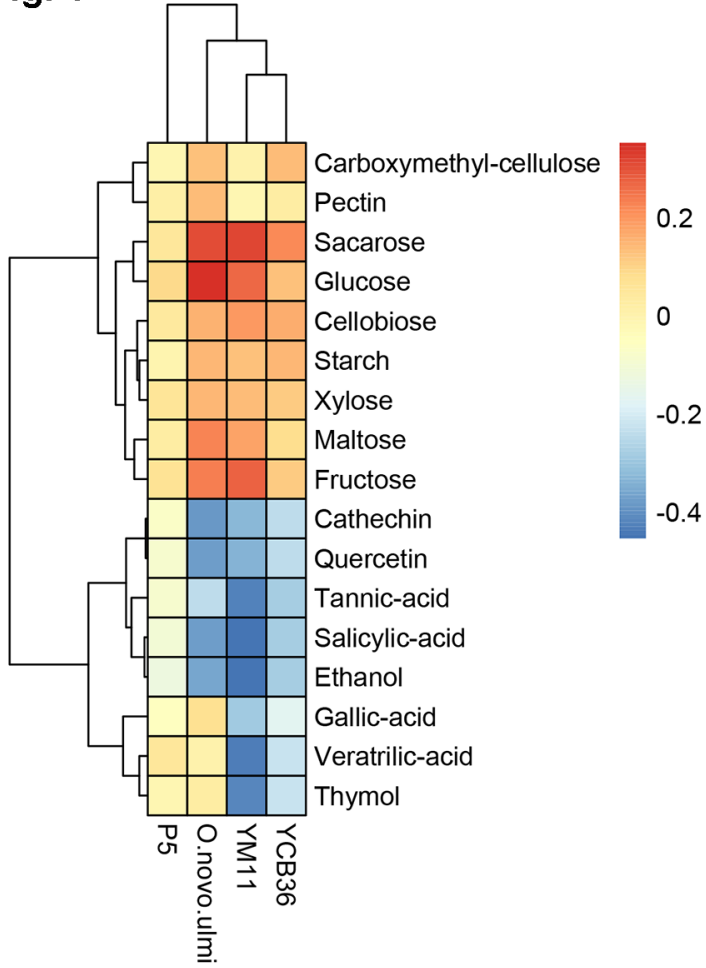


Fig. 2
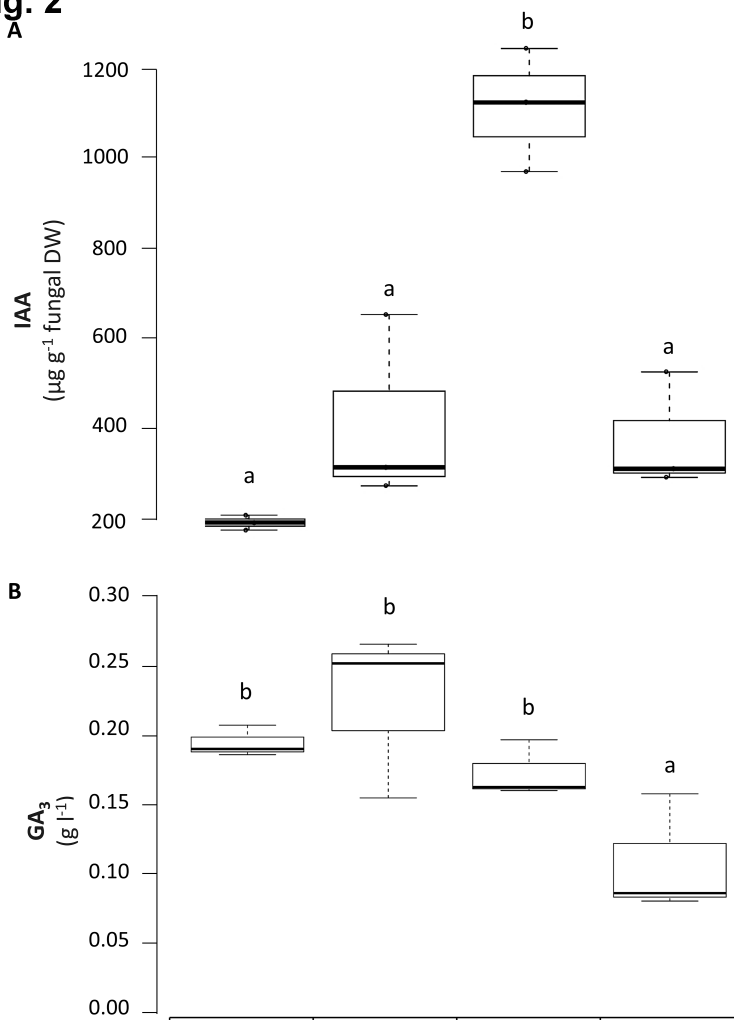

a

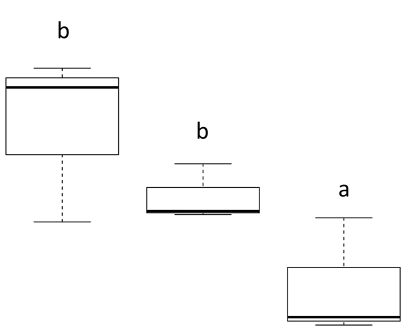

O. novo-ulmi

YCB36

P5

YM11 
Fig. 3

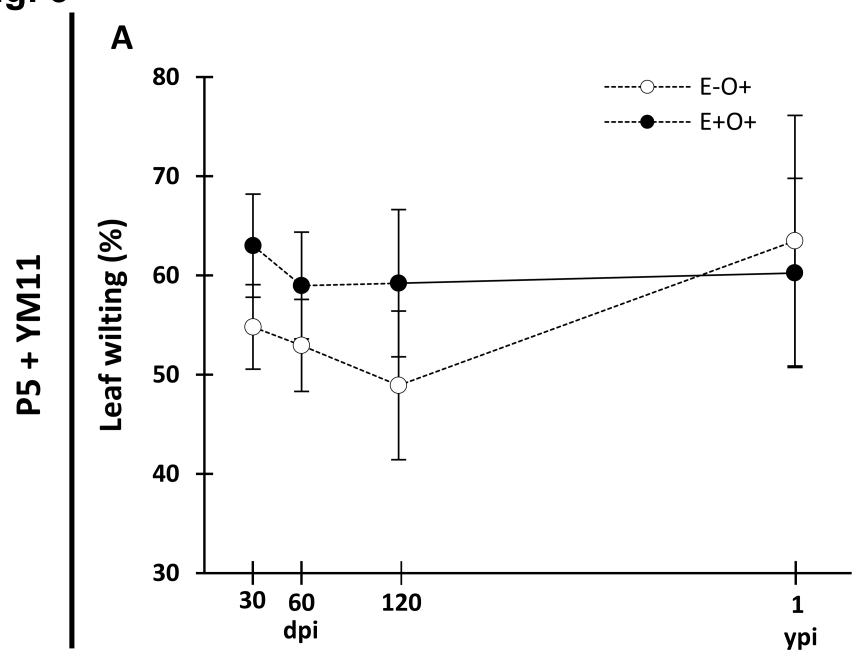

\section{B}
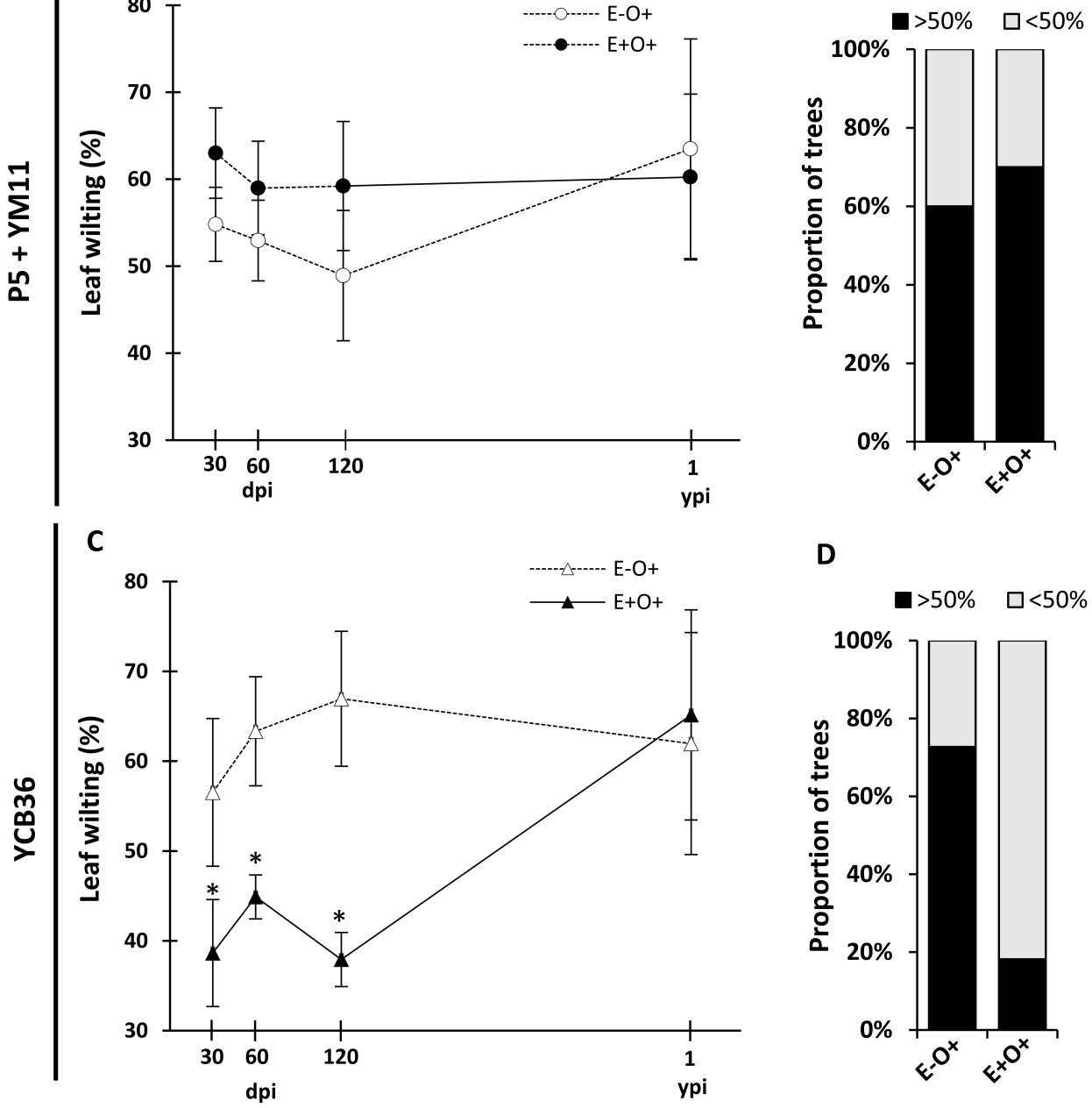
Fig. 4

P5 + YM11

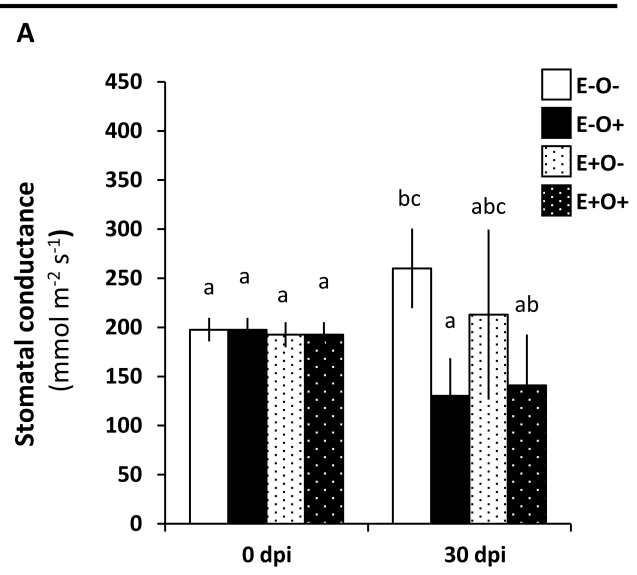

YCB36

B

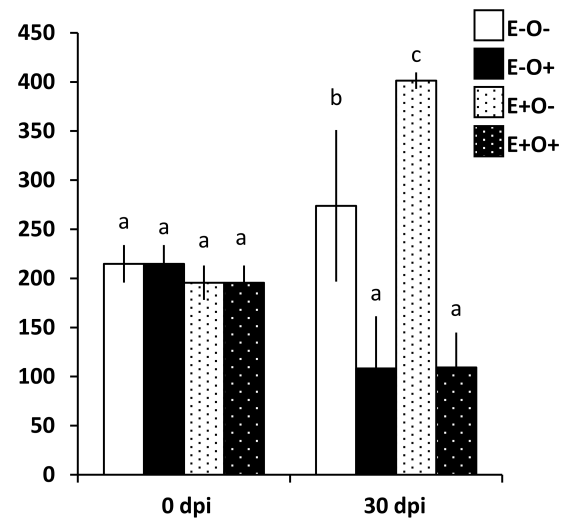


Fig. 5
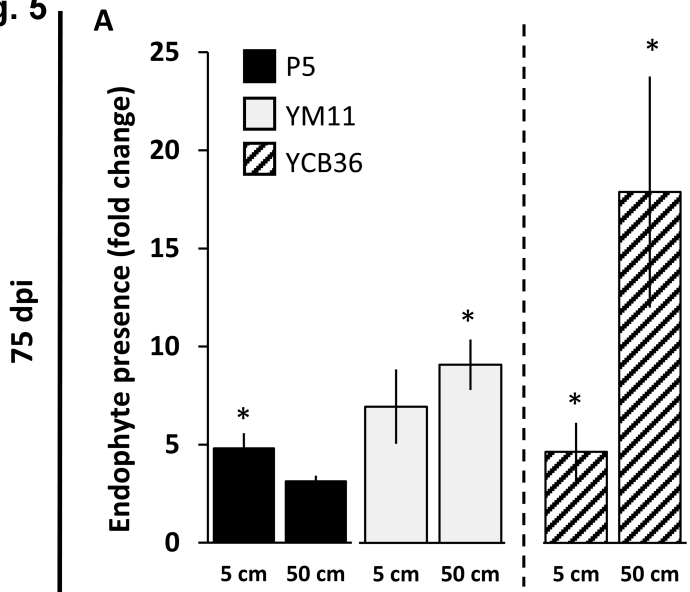

B
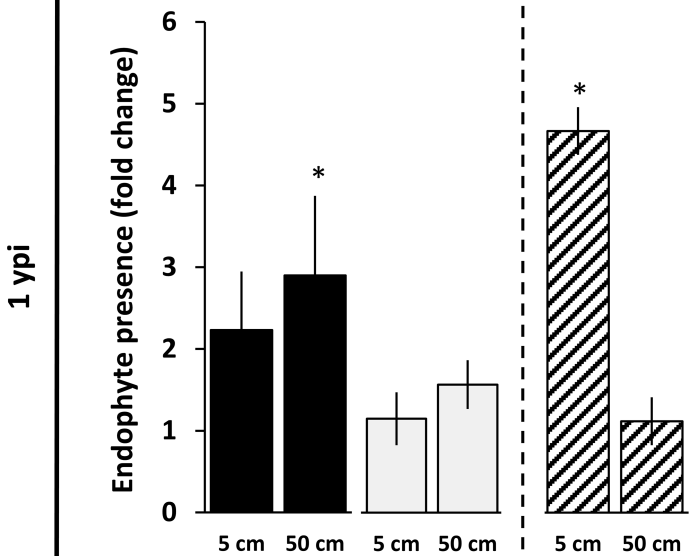
Fig. 6

A $\square$ Non-inoculated

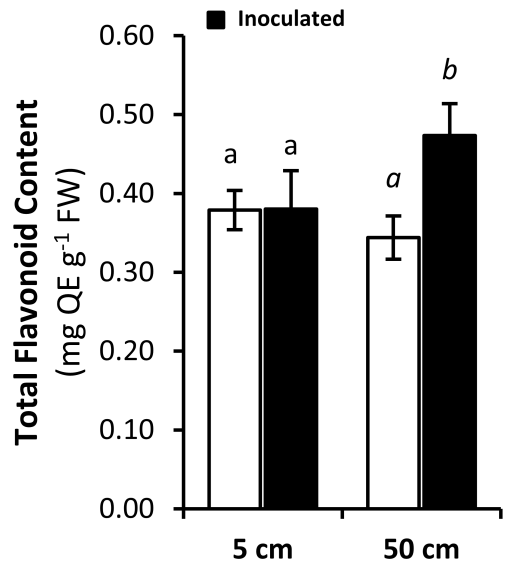

B

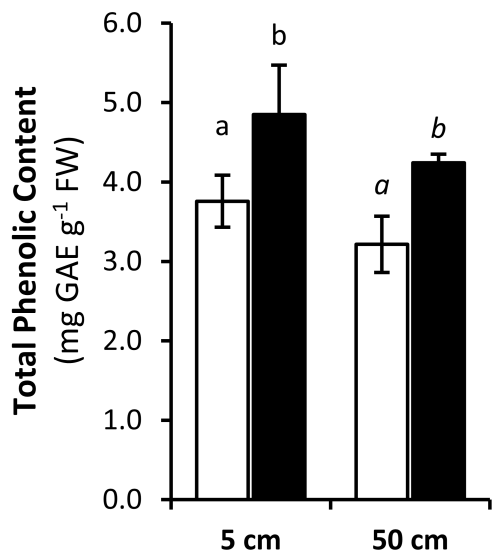

C

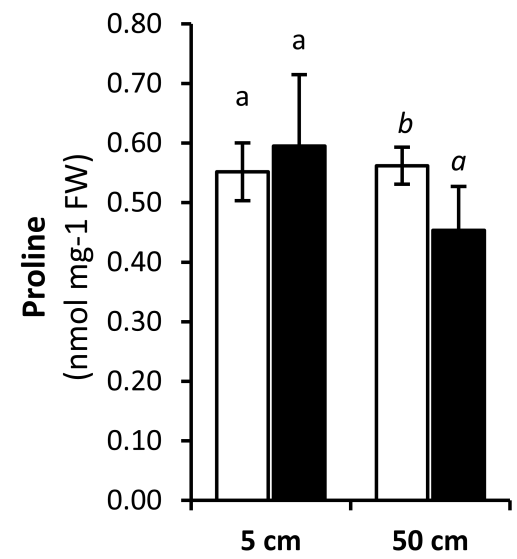


Table 1: Fungal treatment and plant material specifications. E-O-: control plants without endophyte and $O$. novo-ulmi; $\mathrm{E}+\mathrm{O}-$ : endophyte-treated plants without $\mathrm{O}$. novo-ulmi; $\mathrm{E}-\mathrm{O}+\mathrm{O}$. novo-ulmi-treated plants without previous endophyte treatment; $\mathrm{E}+\mathrm{O}+$ : endophyte- and $O$. novo-ulmi-treated plants.

\begin{tabular}{|c|c|c|c|c|}
\hline $\begin{array}{l}\text { Inoculated } \\
\text { endophytes }\end{array}$ & Plant genotype & DED-tolerance level $^{1}$ & Treatment & $\mathbf{N}$ \\
\hline \multirow[t]{12}{*}{ P5+YM11 } & $(\mathrm{M}-\mathrm{CC} 1 \times \mathrm{AL}-\mathrm{AN} 1) .5$ & Susceptible & E-O- & 5 \\
\hline & & & $\mathrm{E}+\mathrm{O}-$ & 5 \\
\hline & & & $\mathrm{E}-\mathrm{O}+$ & 10 \\
\hline & & & $\mathrm{E}+\mathrm{O}+$ & 10 \\
\hline & $(\mathrm{M}-\mathrm{CC} 1 \times \mathrm{AL}-\mathrm{AN} 1) .7$ & Susceptible & E-O- & 5 \\
\hline & & & $\mathrm{E}+\mathrm{O}-$ & 5 \\
\hline & & & $\mathrm{E}-\mathrm{O}+$ & 10 \\
\hline & & & $\mathrm{E}+\mathrm{O}+$ & 10 \\
\hline & $(\mathrm{M}-\mathrm{CC} 1 \times \mathrm{AL}-\mathrm{AN} 1) .8$ & Susceptible & E-O- & 5 \\
\hline & & & $\mathrm{E}+\mathrm{O}-$ & 5 \\
\hline & & & $\mathrm{E}-\mathrm{O}+$ & 10 \\
\hline & & & $\mathrm{E}+\mathrm{O}+$ & 10 \\
\hline \multirow[t]{4}{*}{ YCB36 } & $(\mathrm{M}-\mathrm{CC} 1 \times \mathrm{AL}-\mathrm{AN} 1) .15$ & Susceptible & E-O- & 6 \\
\hline & & & $\mathrm{E}+\mathrm{O}-$ & 12 \\
\hline & & & $\mathrm{E}-\mathrm{O}+$ & 11 \\
\hline & & & $\mathrm{E}+\mathrm{O}+$ & 5 \\
\hline \multirow[t]{2}{*}{---} & Sapporo & Highly tolerant & E-O- & 8 \\
\hline & & & $\mathrm{E}-\mathrm{O}+$ & 8 \\
\hline \multirow[t]{2}{*}{---} & M-PZ3 & Highly susceptible & E-O- & 8 \\
\hline & & & $\mathrm{E}-\mathrm{O}+$ & 8 \\
\hline
\end{tabular}

${ }^{1}$ According to previous susceptibility tests 
Table 2: Top three BLAST hits based on nucleotide megablast of ITS and LSU of rDNA sequences and TEF1 $\alpha$, 6 -tub or actin as protein coding genes. The corresponding GenBank taxa identity and NCBI accession numbers are indicated.

\begin{tabular}{|c|c|c|c|c|c|c|c|c|c|c|}
\hline Strain & Gene & Description & $\begin{array}{l}\text { Max. } \\
\text { Score }\end{array}$ & $\begin{array}{l}\text { Total } \\
\text { score }\end{array}$ & $\begin{array}{l}\text { Query } \\
\text { coverage }\end{array}$ & E-value & Identities & Gaps & $\begin{array}{l}\text { Percentage of } \\
\text { identity }\end{array}$ & Accesion NCBI \\
\hline \multirow{6}{*}{ P5 } & \multirow{3}{*}{ ITS } & Cystobasidium ritchiei & 544 & 544 & 100 & $3.00 \mathrm{E}-155$ & $294 / 294$ & $0 / 294$ & 100 & NR_154854.1 \\
\hline & & Cystobasidium laryngis & 544 & 544 & 100 & $3.00 \mathrm{E}-155$ & $294 / 294$ & $0 / 294$ & 100 & NR_154833.1 \\
\hline & & Cystobasidium pinicola & 538 & 538 & 100 & $1.00 \mathrm{E}-153$ & $293 / 294$ & $0 / 294$ & 99.66 & NR_154834.1 \\
\hline & \multirow{3}{*}{ LSU } & Cystobasidium pallidum & 1517 & 1517 & 92 & 0 & $849 / 865$ & $0 / 865$ & 98.15 & NG_059006.1 \\
\hline & & Cystobasidium pinicola & 1504 & 1504 & 91 & 0 & $848 / 864$ & $7 / 864$ & 98.15 & NG_066178.1 \\
\hline & & Cystobasidium minutum & 1434 & 1434 & 92 & 0 & $834 / 865$ & $0 / 865$ & 96.42 & NG_059005.1 \\
\hline \multirow{9}{*}{ YM11 } & \multirow{3}{*}{ ITS } & Exophiala sp. & 1016 & 1016 & 94 & 0 & $556 / 562$ & $0 / 562$ & 99.45 & EU035420.1 \\
\hline & & Uncultured fungus & 1011 & 1011 & 94 & 0 & $555 / 562$ & $0 / 562$ & 99.27 & FJ820808.1 \\
\hline & & Uncultured fungus & 996 & 996 & 94 & 0 & $552 / 561$ & $1 / 561$ & 98.9 & KF800433.1 \\
\hline & \multirow{3}{*}{ LSU } & Exophiala sp. & 1522 & 1522 & 91 & 0 & $829 / 832$ & $1 / 832$ & 99.64 & EU035420.1 \\
\hline & & Knufia sp. & 1515 & 1515 & 91 & 0 & $827 / 831$ & $1 / 831$ & 99.52 & MF062037.1 \\
\hline & & Knufia cryptophialidica & 1511 & 1511 & 91 & 0 & $827 / 832$ & $1 / 832$ & 99.4 & NG_067522.1 \\
\hline & \multirow{3}{*}{ TEF1 $\alpha$} & Knufia peltigerae & 841 & 841 & 94 & 0 & $541 / 584$ & $2 / 584$ & 92.64 & KP175006.1 \\
\hline & & Knufia peltigerae & 824 & 824 & 94 & 0 & $538 / 584$ & $2 / 584$ & 92.12 & KP175005.1 \\
\hline & & Knufia sp & 797 & 797 & 94 & 0 & $532 / 583$ & $0 / 583$ & 91.25 & FJ161099.1 \\
\hline \multirow{15}{*}{ YCB36 } & \multirow{3}{*}{ ITS } & Dothydeomycetes & 1650 & 1650 & 87 & 0 & $932 / 951$ & $9 / 951$ & 98.00 & KX611035.1 \\
\hline & & Ascomycota & 1639 & 1639 & 86 & 0 & $926 / 945$ & $9 / 945$ & 97.99 & KX611067.1 \\
\hline & & Phaeosphaeriaceae & 1611 & 1611 & 84 & 0 & $902 / 916$ & $5 / 916$ & 98.47 & MG208007.1 \\
\hline & \multirow{3}{*}{ LSU } & Hydeomyces pinicola & 1561 & 1561 & 81 & 0 & $855 / 860$ & $0 / 860$ & 99.41 & MK522496.1 \\
\hline & & Ophiobolus erythrosporus & 1552 & 1552 & 82 & 0 & $857 / 866$ & $0 / 860$ & 98.96 & KM014665.1 \\
\hline & & Fungal sp. & 1528 & 1526 & 82 & 0 & $853 / 866$ & $1 / 866$ & 98.49 & MH875255.1 \\
\hline & \multirow{3}{*}{ TEF1 $\alpha$} & Hydeomyces desertipleosporoides & 425 & 425 & 53 & $9.00 \mathrm{E}-115$ & $257 / 281$ & $0 / 281$ & 91.45 & MK290848.1 \\
\hline & & Dothideomycetes sp. & 414 & 414 & 53 & $2.00 \mathrm{E}-111$ & $255 / 281$ & $0 / 281$ & 90.74 & MK523386.1 \\
\hline & & Hawksworthiana clematidicola & 414 & 414 & 53 & $2.00 \mathrm{E}-111$ & $255 / 281$ & $0 / 281$ & 90.74 & MG829202.1 \\
\hline & \multirow{3}{*}{ tub2/BenA } & Paraphoma sp. & 270 & 270 & 100 & $2.00 \mathrm{E}-68$ & $215 / 248$ & $11 / 248$ & 86.69 & MG779455.1 \\
\hline & & Paraphoma sp. & 265 & 265 & 100 & $9.00 \mathrm{E}-67$ & $214 / 248$ & $11 / 248$ & 86.29 & MG779458.1 \\
\hline & & Paraphoma sp. & 265 & 265 & 100 & $9.00 \mathrm{E}-67$ & $214 / 248$ & $11 / 248$ & 86.29 & MG779456.1 \\
\hline & \multirow{3}{*}{ actin } & Chaetosphaeronema sp. & 110 & 110 & 81 & $3.00 \mathrm{E}-20$ & $115 / 142$ & $5 / 142$ & 80.99 & MG677982.1 \\
\hline & & Phoma haematocycla & 104 & 104 & 73 & $1.00 \mathrm{E}-18$ & $104 / 127$ & $4 / 127$ & 81.89 & КТ309156.1 \\
\hline & & Pleospora flavigena & 82.4 & 82.4 & 30 & $6.00 \mathrm{E}-12$ & $50 / 53$ & $0 / 53$ & 94.34 & JF740108.1 \\
\hline
\end{tabular}


Table 3: Influence of fungal endophytes on $O$. novo-ulmi growth in the dual culture assay (day 12 of incubation), volatiles (VOCs) assay (day 10) and antibiosis assay (day 10). Different letters in the same row indicate significant differences between fungi, according to Fisher's post-hoc test $(P<0.05)$.

\begin{tabular}{llcccc} 
& & \multicolumn{4}{c}{ O. novo-ulmi growth } \\
\cline { 3 - 6 } Assay & Units & Control & YCB36 & P5 & YM11 \\
\hline Dual culture & $\mathrm{cm}^{2}$ & $25.567 \pm 3.69^{\mathrm{c}}$ & $15.48 \pm 1.03^{\mathrm{a}}$ & $18.95 \pm 0.48^{\mathrm{b}}$ & $25.54 \pm 1.72^{\mathrm{c}}$ \\
VOCs & $\mathrm{cm}^{2}$ & $30.85 \pm 3.27^{\mathrm{c}}$ & $19.98 \pm 1.64^{\mathrm{a}}$ & $24.67 \pm 1.92^{\mathrm{b}}$ & $29.29 \pm 1.46^{\mathrm{c}}$ \\
Antibiosis & OD & $0.150 \pm 0.001^{\mathrm{c}}$ & $0.062 \pm 0.003^{\mathrm{a}}$ & $0.134 \pm 0.011^{\mathrm{b}}$ & $0.101 \pm 0.008^{\mathrm{b}}$ \\
\hline
\end{tabular}


Table 4: Protease and chitinase activities, siderophore and hydrogen cyanide production, and phosphate solubilisation in in vitro assays of the fungal endophytes and the pathogen at the end of the experiment (day 20). Different letters in the same row indicate significant differences between fungi, according to Fisher's post-hoc test $(P<0.05)$.

\begin{tabular}{llllll}
\hline & & \multicolumn{4}{c}{ Fungal strain } \\
\cline { 3 - 6 } Activity & Units & O. novo-ulmi & YCB36 & P5 & YM11 \\
\hline Protease & $\mathrm{cm}^{2}$ (halo) & $28.73 \pm 1.96^{\mathrm{c}}$ & $10.28 \pm 2.48^{\mathrm{b}}$ & $1.33 \pm 0.06^{\mathrm{a}}$ & $5.75 \pm 0.71^{\mathrm{b}}$ \\
Chitinase & $\mathrm{cm}^{2}$ (halo) & $6.46 \pm 1.93^{\mathrm{a}}$ & $49.85 \pm 1.63^{\mathrm{b}}$ & negative & negative \\
Siderophore & $\mathrm{cm}^{2}$ (halo) & $5.39 \pm 0.98^{\mathrm{a}}$ & $7.90 \pm 0.44^{\mathrm{b}}$ & negative & negative \\
Hydrogen cyanide & positive/negative & negative & negative & negative & negative \\
Phosphate solubilization & $\mathrm{cm}^{2}$ (halo) & negative & negative & negative & negative \\
\hline
\end{tabular}


Fig. $\$ 1$

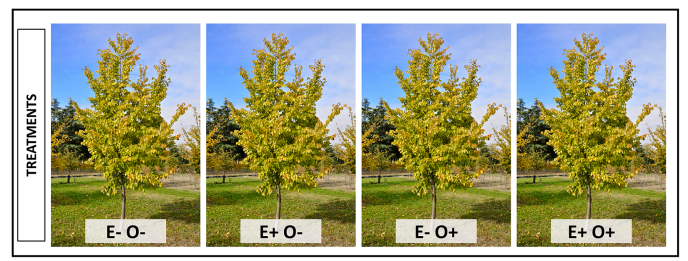

-15 d.p.i.

0 d.p.i.

o. novo-ulmi inoculation
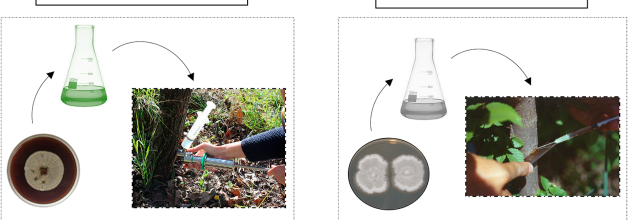

30 d.p.i.

60 d.p.i.

120 d.p.i.

Leaf wilting evaluation

SS, starch, proline, flavonoids and phenolic content

ì qPCR endophyte presence
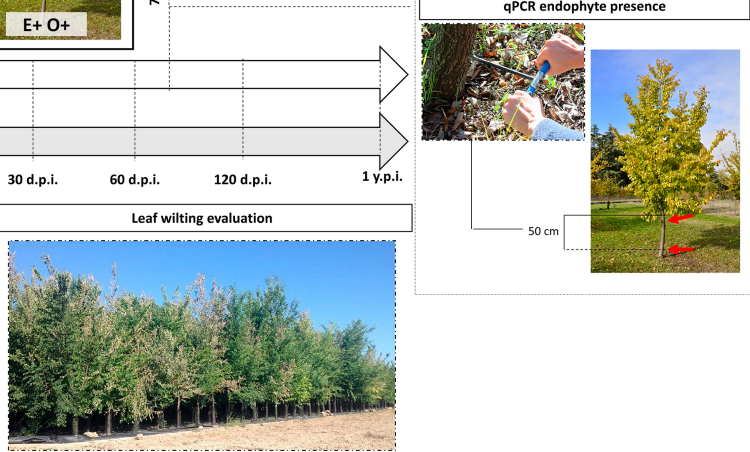
Fig. S2
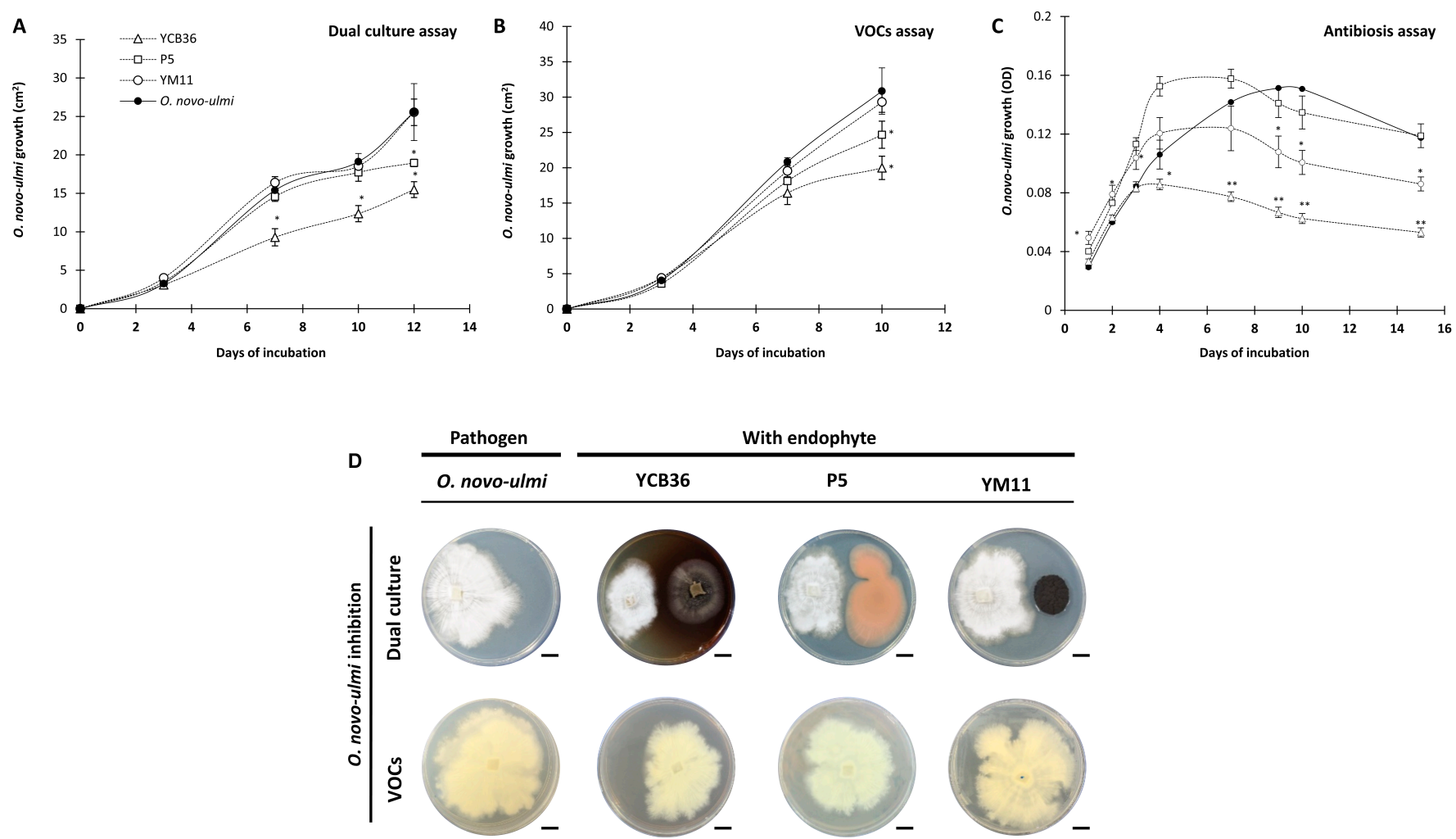
Fig. S3

Pathogen

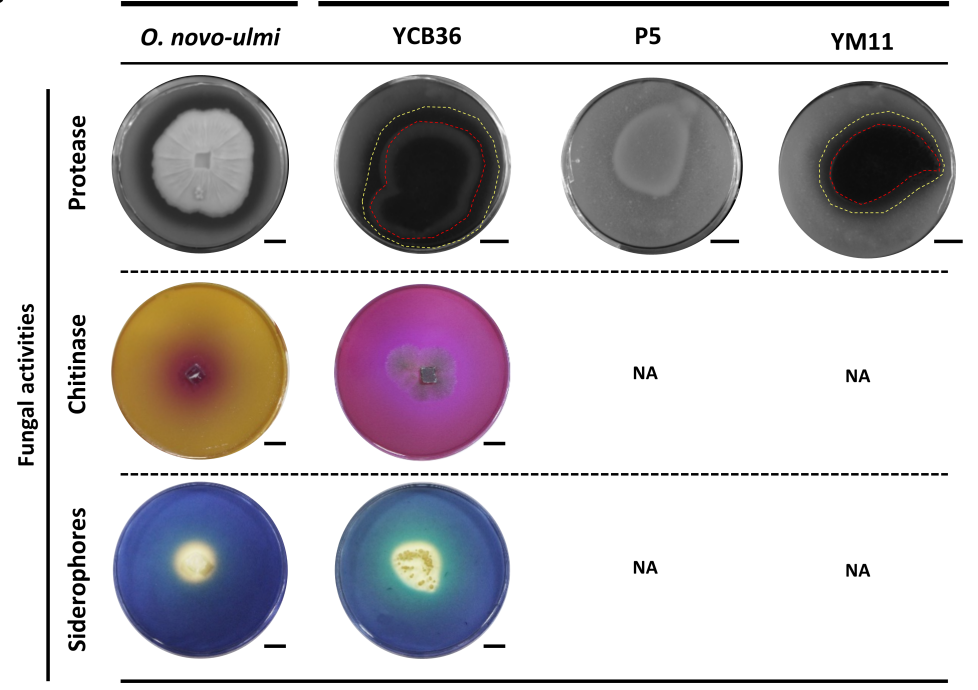

Endophytes

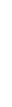

